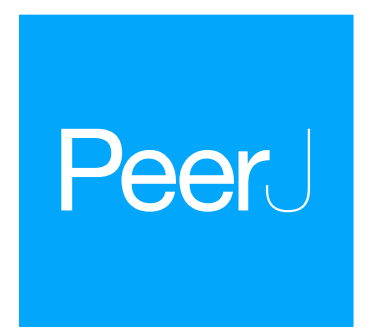

\title{
Cortical modulation of pupillary function: systematic review
}

\author{
Costanza Peinkhofer ${ }^{1,2, *}$, Gitte M. Knudsen ${ }^{1,3,4}$, Rita Moretti ${ }^{2,5}$ and \\ Daniel Kondziella ${ }^{1,4,6, *}$ \\ ${ }^{1}$ Department of Neurology, Rigshospitalet, Copenhagen University Hospital, Copenhagen, Denmark \\ ${ }^{2}$ Medical Faculty, University of Trieste, Trieste, Italy \\ ${ }^{3}$ Neurobiology Research Unit, Rigshospitalet, Copenhagen University Hospital, Copenhagen, Denmark \\ ${ }^{4}$ Faculty of Health and Medical Science, University of Copenhagen, Copenhagen, Denmark \\ ${ }^{5}$ Department of Medical, Surgical and Health Sciences, Neurological Unit, Trieste University Hospital, \\ Cattinara, Trieste, Italy \\ ${ }^{6}$ Department of Neuroscience, Norwegian University of Technology and Science, Trondheim, Norway \\ These authors contributed equally to this work.
}

\section{ABSTRACT}

Background. The pupillary light reflex is the main mechanism that regulates the pupillary diameter; it is controlled by the autonomic system and mediated by subcortical pathways. In addition, cognitive and emotional processes influence pupillary function due to input from cortical innervation, but the exact circuits remain poorly understood. We performed a systematic review to evaluate the mechanisms behind pupillary changes associated with cognitive efforts and processing of emotions and to investigate the cerebral areas involved in cortical modulation of the pupillary light reflex.

Methodology. We searched multiple databases until November 2018 for studies on cortical modulation of pupillary function in humans and non-human primates. Of 8,809 papers screened, 258 studies were included.

Results. Most investigators focused on pupillary dilatation and/or constriction as an index of cognitive and emotional processing, evaluating how changes in pupillary diameter reflect levels of attention and arousal. Only few tried to correlate specific cerebral areas to pupillary changes, using either cortical activation models (employing micro-stimulation of cortical structures in non-human primates) or cortical lesion

Submitted 30 January 2019

Accepted 26 March 2019

Published 7 May 2019

Corresponding author

Daniel Kondziella,

daniel_kondziella@yahoo.com

Academic editor

Stephen Macknik

Additional Information and Declarations can be found on page 18

DOI 10.7717/peerj.6882

Copyright

2019 Peinkhofer et al.

Distributed under

Creative Commons CC-BY 4.0

OPEN ACCESS models (e.g., investigating patients with stroke and damage to salient cortical and/or subcortical areas). Results suggest the involvement of several cortical regions, including the insular cortex (Brodmann areas 13 and 16), the frontal eye field (Brodmann area 8 ) and the prefrontal cortex (Brodmann areas 11 and 25), and of subcortical structures such as the locus coeruleus and the superior colliculus.

Conclusions. Pupillary dilatation occurs with many kinds of mental or emotional processes, following sympathetic activation or parasympathetic inhibition. Conversely, pupillary constriction may occur with anticipation of a bright stimulus (even in its absence) and relies on a parasympathetic activation. All these reactions are controlled by subcortical and cortical structures that are directly or indirectly connected to the brainstem pupillary innervation system.

Subjects Anatomy and Physiology, Neurology, Ophthalmology

Keywords Emotion, Cognition, Brain injury, Frontal eye field, Pupillary light reflex, Stroke, Micro stimulation 


\section{INTRODUCTION}

The pupillary light reflex is a polysynaptic reflex that requires cranial nerves II and III, as well as central brainstem connections (Kawasaki, 1999). Light falling into one eye stimulates retinal photoreceptors, bipolar cells and subsequently retinal ganglion cells whose axons form the optic nerve. Some of these axons terminate in the pretectum of the mesencephalon and pretectal neurons project further to the Edinger-Westphal nuclei. Then, preganglionic parasympathetic axons synapse with ciliary ganglion neurons which in turn send postganglionic axons to innervate the pupillary constrictor muscles of both eyes. Conversely, pupillary dilatation relies on the sympathetic system which consists of pre-ganglionic fibers projecting from the hypothalamus to the superior cervical ganglion and post-ganglionic fibers projecting to the iris dilator muscles, via ciliary nerves (Kawasaki, 1999).

In addition to brainstem pathways, there exists also a cortical component of pupillary innervation. For instance, emotional responses such as surprise and cognitive processes such as decision making, memory recall and mental arithmetic may produce pupillary dilation (Steinhauer, Condray \& Kasparek, 2000; Simpson \& Hale, 1969; De Gee, Knapen \& Donner, 2014). Pupillary function may be assessed as changes in pupillary size relative to resting state diameter or alterations of the light reflex in terms of reflex amplitude and latency (i.e., time from light stimulus to pupillary constriction). Cognitive scientists and psychologists have used measurements of pupillary diameters since the 1960ies to monitor mental processes in healthy volunteers and people with a wide range of neurological and psychiatric disorders, including Alzheimer's disease, autism and anxiety (Bittner et al., 2014; Lim et al., 2016; Bakes, Bradshaw \& Szabadi, 1990; Krach et al., 2015). Testing of emotional processes usually involves neutral versus emotionally salient stimuli, e.g., pictures of everyday life objects versus pictures evoking sadness, anger or happiness, whereas cognitive processes are investigated with tasks such as arithmetic calculations and memory recall tests (Steinhauer, Condray \& Kasparek, 2000; Van Steenbergen \& Band, 2013). In addition, neuroimaging, including computed tomography (CT) and magnetic resonance imaging (MRI), has been used to correlate changes in pupillary functions with cerebral lesions in patients with stroke and other brain disorders (Peinkhofer et al., 2018). In the same vein, electrical stimulation of cortical areas such as the frontal eye field (Brodmann area 8 ) has been investigated to correlate pupillary and cortical function in non-human primates (Becket Ebitz \& Moore, 2017).

Although pupillary function is of considerable interest to neurologists, ophthalmologists, neuroscientists, physiologists and psychologists, the exact mechanisms of supratentorial modulation of pupillary function remains poorly understood. Previous (unsystematic) reviews have focused mainly on cognitive aspects such as attention but not on pupillary cortical control (Laeng, Sirois \& Gredebäck, 2012; Granholm \& Steinhauer, 2004; Van der Wel \& Van Steenbergen, 2018).

Therefore, in this review we aimed to identify (a) the cortical and subcortical areas and (b) the behavior and cognitive processes that modulate pupillary function in humans and non-human primates. 


\section{METHODS}

We performed a systematic review of the literature using a predefined search strategy and phrasing research objectives with the PICO approach (a standardized way of defining research questions, focusing on Patients, Intervention, Comparison, and Outcome) (Schardt, Adams \& Owens, 2007). The review was registered with PROSPERO registration number CRD42018116653 (https://www.crd.york.ac.uk/prospero/). The review protocol can be accessed from the online File S1.

\section{Objectives}

\section{Primary research objectives}

PICO 1: In patients with focal cerebral lesions due to e.g., stroke, traumatic brain injury or brain surgery $(\mathrm{P})$, does involvement of salient cortical and subcortical gray matter areas, including but not limited to the prefrontal eye field, insular cortex and thalamus (I), as compared to healthy controls or neurological patients without such lesions (C), lead to changes of pupillary function, i.e., the light reflex or resting state pupillary diameter $(\mathrm{O})$ ?

PICO 2: In healthy human subjects (P), do cognitive efforts (e.g., decision making or mental arithmetic) and processing of non-painful emotional stimuli (I), as compared to task negative and emotionally neutral conditions (C), lead to changes of pupillary function, i.e., the light reflex or resting state pupillary diameter $(\mathrm{O})$ ?

\section{Secondary research objectives}

PICO 3: In non-human primates $(\mathrm{P})$, does invasive experimental manipulation (e.g., electrical stimulation) of cortical and subcortical gray matter areas (I), as compared to absence of stimulation $(\mathrm{C})$, lead to changes of pupillary function, i.e., the light reflex or resting state pupillary diameter $(\mathrm{O})$ ?

PICO 4: In non-human primates (P), do cognitive efforts such as decision making and processing of non-painful emotional stimuli (I), as compared to task negative and emotionally neutral conditions (C), lead to changes of pupillary function, i.e., the light reflex or resting state pupillary diameter $(\mathrm{O})$ ?

\section{Eligibility criteria Types of studies}

We evaluated all cross-sectional or longitudinal, retrospective or prospective, observational, clinical and research studies as well as interventional trials, including experimental animal work on non-human primates, reporting on pupillary function as related to modulation by cortical and subcortical lesions or stimulations, as well as modulation by cognitive and emotional processes. We excluded reviews and meta-analysis, non-original studies and studies with $n=\leq 15$ human subjects.

\section{Participants}

All patients aged $\geq 18$ years with ischemic or hemorrhagic stroke, brain trauma and/or brain surgery as well as healthy subjects studied in order to correlate pupillary function with focal lesions and/or to specific cognitive or emotional cerebral processing related to experimental invasive or non-invasive stimulation were included. For secondary research 
questions we included non-human primates with or without cerebral lesions studied to correlate pupillary function with cerebral cortical and/or subcortical gray matter areas and with specific cognitive or emotional cerebral processing related to experimental invasive or non-invasive stimulation. For exclusion criteria, the reader is referred to the protocol review (File S1).

\section{Outcome measures}

The main outcome measure was a change in pupillary function, i.e., either a variation of the pupillary diameter or a difference in the light reflex (e.g., a longer latency period), compared to a baseline value or a control group.

\section{Index tests and interventions}

The index tests comprised neuroimaging (CT, MRI including functional MRI, PET, SPECT), post-mortem examination revealing the extent of brain lesions, quantitative pupillometry (Eye Link 1000 and similar devices) and visual inspection of pupillary function. Concerning interventions, we included all studies with invasive procedures such as electrical cortical and/or subcortical stimulation or induced cerebral lesions as well as non-invasive interventions such as cognitive and emotional tasks or sensorial stimulation of healthy humans, humans with specific cerebral lesions (see above) and non-human primates.

\section{Search methods for identification of studies Electronic literature search strategy}

We searched MEDLINE (PubMed), EMBASE and Scopus for relevant literature from January 1st, 1960 to November 15th, 2018. As a search strategy, we used both free textwords (TW) and controlled terms obtained with medical subject headings (MeSH). For search strategy and search terms refer to review protocol (File S1). Reference lists were manually screened for further relevant articles.

\section{Data collection and analysis Selection of studies, data extraction and management}

Titles and abstracts were first reviewed. Eligible studies were assessed on the basis of their full text and referenced using Mendeley Software (https://www.mendeley.com). Data were extracted by the first author and checked by the senior author. Preferred Reported Items for Systematic reviews and Meta-analyses (PRISMA) guidelines were followed (Liberati et al., 2009) (see File S2).

\section{RESULTS}

We screened 8809 papers in the primary search; three additional publications were manually added. After the exclusion of duplicates, studies with different topic and subjects below 18 years of age, 856 citations were screened for eligibility criteria on an abstract basis. Three-hundred and fifty-five articles were analyzed with a full text review, and 258 studies were included for the final analysis. Figure 1 provides a flowchart of the literature search. 


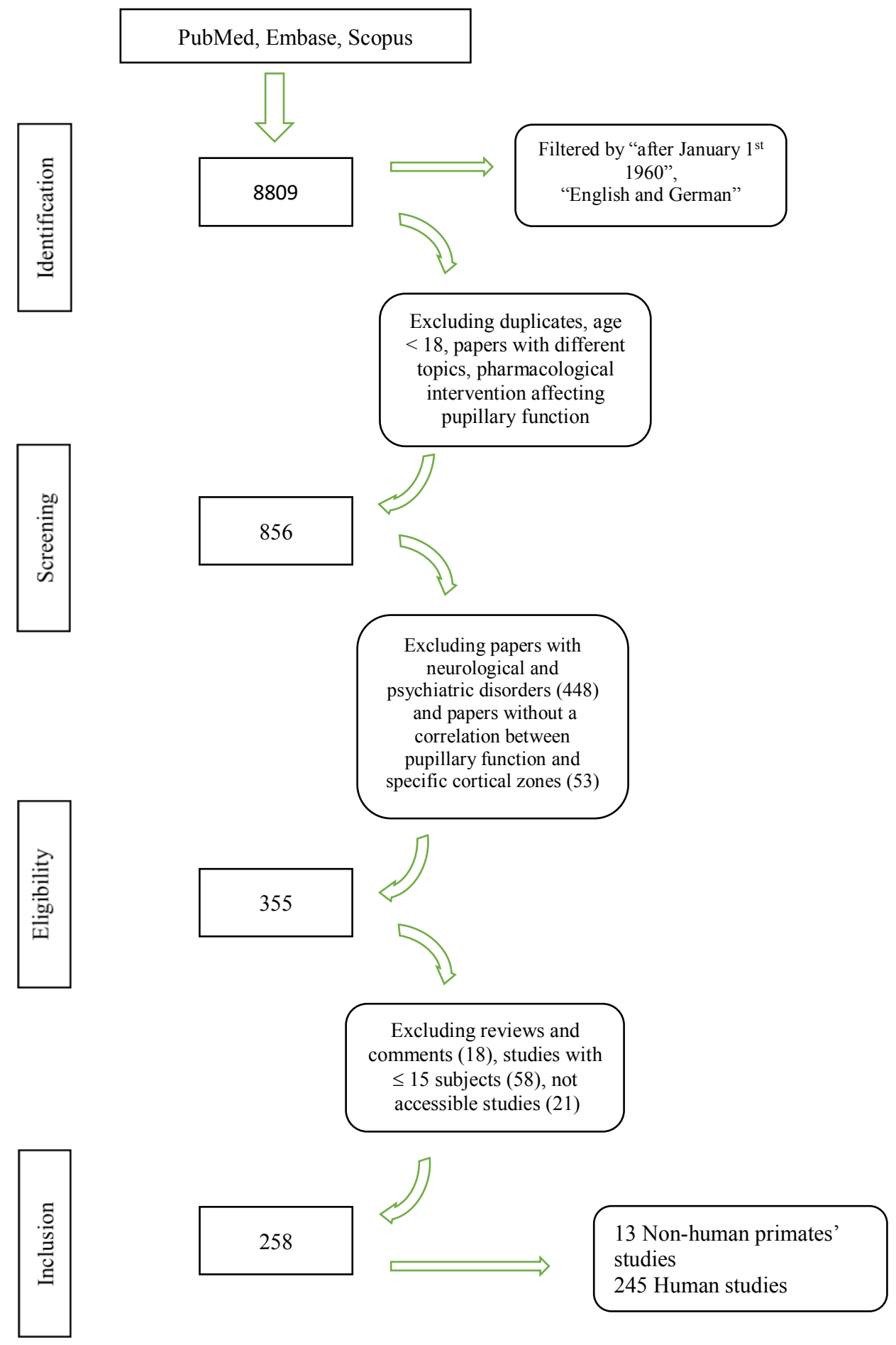

Figure 1 Flowchart of the literature search. Flowchart showing the literature search and the study selection process.

Full-size DOI: 10.7717/peerj.6882/fig-1 


\section{PICO 1: Pupillary changes associated with cortical lesions in humans}

Cerebral areas that may modulate the pupillary light reflex were examined in three studies involving patients with cerebrovascular lesions. One study assessed pupillary dilatation as an index of arousal and reward processing during an oculomotor capture task (Manohar et al., 2016), revealing diminished pupillary dilatation in patients with chronic ventromedial prefrontal damage (Brodmann areas 11 and 25) due to subarachnoid hemorrhage as compared to healthy controls. Another, retrospective study of patients with cerebrovascular lesions (Herman, 1975), showed persistent anisocoria associated with lesions involving the right or left middle cerebral artery (MCA) territory in the absence of oculomotor nerve compression, but neuroimaging was not available and study results should be cautiously interpreted. In contrast, ischemic stroke lesions were verified using CT in a recent, prospective study, in which investigators assessed how anterior circulation strokes involving the prefrontal eye field (Brodmann area 8) and/or the insular cortex (Brodmann areas 13 and 16) affected pupillary function. Patients with strategic infarcts in either of these areas showed subtle differences during the dilatation phase of the pupillary light reflex, but not patients with infarcts in other cerebral regions or neurologically normal controls (Peinkhofer et al., 2018).

\section{PICO 2: Pupillary changes associated with cognitive and emotional activity in humans}

Most of the papers $(n=242)$ referred to changes in pupillary diameter during cognitive and/or emotional processes in humans. One hundred eighty-one (75\%) assessed pupillary diameter as an index of mental effort during different cognitive activities. Sixty-one studies (25\%) focused on the relationship between emotional arousal and pupillary reaction (Table 1).

\section{Pupillary constriction: cognition and emotions}

Constriction was observed in response to specific attentional tasks, where subjects had to focus on luminous stimuli such as bright surfaces (Turi, Burr \& Binda, 2018; Mathôt et al., 2014), illusory or mental images of brightness (Laeng \& Endestad, 2012; Laeng \& Sulutvedt, 2014) and pictures of the sun (Sperandio, Bond \& Binda, 2018; Naber \& Nakayama, 2013) as opposed to darker stimuli or scattered pictures of the sun (Sperandio, Bond \& Binda, 2018; Naber \& Nakayama, 2013). Following the same concept, constriction was also recorded for visually or auditory words conveying luminance (e.g., "lamp") compared to words conveying darkness (e.g., "night") (Mathôt, Grainger \& Strijkers, 2017).

A smaller pupillary diameter was also considered an index of novelty during memory formation (i.e., pupillary constriction associated with remembered words) and memory retrieval (i.e., pupillary constriction with forgotten words) (Naber et al., 2013). Pupillary constriction may also occur with certain affective responses activating the parasympathetic system such as disgust (Ayzenberg, Hickey \& Lourenco, 2018).

\section{Pupillary dilatation: cognition}

Several studies recorded pupillary dilatation with memory tests, revealing how a change in diameter is related to memory retrieval. Pupillary dilatation occurred during testing 
Table 1 Human studies of the influence of cognitive and emotional processes on pupillary function. Every study is categorized depending on the specific task required and/or type of stimuli used (first column on the left) and on the observed pupillary response (central and right column).

Pupillary Dilation
Pupillary responses other than dilation

\section{COGNITION}

Memory

Attention including orienting reflex

Language processing and learning
Pupillary constriction (Naber et al., 2013)

Pupillary constriction (Turi, Burr \& Binda, 2018; Mathôt et al., 2014; Laeng \& Endestad, 2012; Laeng \& Sulutvedt, 2014; Sperandio, Bond \& Binda, 2018; Naber \& Nakayama, 2013)

Pupillary constriction (Mathôt, Grainger \& Strijkers, 2017)
Brocher \& Graf (2017), Brocher \& Graf (2016), Gomes, Montaldi \& Mayes (2015), Heaver \& Hutton (2011), Johansson et al. (2018), Kafkas \& Montaldi (2011), Kafkas \& Montaldi (2015), Kafkas \& Montaldi (2012), Mill, O’Connor \& Dobbins (2016), Montefinese et al. (2013), Otero, Weekes \& Hutton (2011), Bradley \& Lang (2015), Herweg, Sommer \& Bunzeck (2017), Võ et al. (2008), Weiss et al. (2016), Sher (1971), Starc, Anticevic \& Repovš (2017), Unsworth \& Robison (2018b), Johnson (1971), Klingner, Tversky \& Hanrahan (2011), Taylor (1981), Van Gerven et al. (2004), Wong \& Epps (2016), Tsukahara, Harrison \& Engle (2016), Bijleveld (2018), Cabestrero, Crespo \& Quirós (2009), Granholm et al. (1996), Magliero (1983), Piquado, Isaacowitz \& Wingfield (2010), Van Rijn et al. (2012), Morey (2018), Robison \& Unsworth (2018), Boyer et al. (2018) and Bergt et al. (2018)

Liao et al. (2016), Marois et al. (2018), Steiner \& Barry (2011), Stelmack \& Siddle (1982), Franklin et al. (2013), Hopstaken et al. (2016), Huijser, Van Vugt \& Taatgen (2018), Smallwood et al. (2011), Unsworth \& Robison (2016), Brink Van Den, Murphy \& Nieuwenhuis (2016), Gouraud, Delorme \& Berberian (2018a), Unsworth \& Robison (2018a), Gouraud, Delorme \& Berberian (2018b), Kang, Huffer \& Wheatley (2014), Kang \& Wheatley (2017), Wierda et al. (2012), Willems, Herdzin \& Martens (2015), Geva et al. (2013), Alnaes et al. (2014), Brocher et al. (2018), Chatham et al. (2012), Hosseini et al. (2017), Koenig, Uengoer \& Lachnit (2018), McCloy et al. (2017), Nunnally et al. (1967), Tylén et al. (2012), Unsworth, Robison \& Miller (2018), Wahn et al. (2016), Yellin, Berkovich-Ohana \& Malach (2015), Chiew \& Braver (2013), Wykowska et al. (2013), Sulutvedt, Mannix \& Laeng (2018), Quirins et al. (2018) and Campbell, Toth \& Brady (2018)

Mathôt, Grainger \& Strijkers (2017), Reinhard, Lachnit \& König (2006), Koelewijn et al. (2012b), Winn, Edwards \& Litovsky (2015), Zekveld, Kramer \& Festen (2010), Zekveld, Festen \& Kramer (2013), Zekveld et al. (2014a), Zekveld \& Kramer (2014), Zekveld et al. (2014b), Kuchinke et al. (2007), Papesh \& Goldinger (2012), Schmidtke (2014), Colman \& Paivio (1970), Engelhardt, Ferreira \& Patsenko (2010), Paivio \& Simpson (1966), Simpson \& Paivio (1968), Ben-Nun (1986), Schluroff et al. (1986), Tromp, Hagoort \& Meyer (2016), Borghini \& Hazan (2018), Iacozza, Costa \& Duñabeitia (2017), Foroughi, Sibley \& Coyne (2017), Shalev et al. (2018), Reinhard \& Lachnit (2002), Van Der Meer et al. (2003), Kahya et al. (2018), Ariel \& Castel (2014), Bayer, Sommer \& Schacht (2011), Beatty \& Wagoner (1978), Carver (1971), Causse et al. (2010), Demberg \& Sayeed (2016), Just \& Carpenter (1993), Koelewijn et al. (2012a), Fernández et al. (2016), Hyona, Tommola \& Alaja (1995), Hoffing \& Seitz (2015), Koelewijn et al. (2015), Kramer et al. (2013), Kuipers \& Thierry (2011), Laeng et al. (2011), Lobben \& Bochynska (2018), Ojha, Indurkhya \& Lee (2017), Metalis et al. (1980), Scheepers et al. (2013), Sevilla, Maldonado \& Shalóm (2014), Zellin et al. (2011), White \& French (2017) and Zekveld et al. (2018) 
Table 1 (continued)

\section{Pupillary Dilation}

Pupillary responses other than dilation

Mental arithmetic

Decision making including uncertainty

Various:

-Deception

-Time and preparatory activity

-Conflict processing

-Error

-Mental work-

load

\section{EMOTION/AROUSAL}

Preference for

Faces

Political candi-

dates

$V$ isual arts

Alcoholic bever-

ages
Steinhauer, Condray \& Kasparek (2000), Klingner, Tversky \& Hanrahan (2011), Bradshaw (1967), Chen \& Epps (2014), Marquart \& De Winter (2015), Szulewski, Roth \& Howes (2015), Szulewski et al. (2017), Steinhauer et al. (2004) and Annerer-Walcher, Körner \& Benedek (2018)

De Gee, Knapen \& Donner (2014), Mill, O'Connor \& Dobbins (2016), Szulewski, Roth \& Howes (2015), Szulewski et al. (2017), Verney, Granholm \& Dionisio (2001), Verney, Granholm \& Marshall (2004), Wolff et al. (2015), Reilly et al. (2018), Trani \& Verhaeghen (2018), Stojmenova \& Sodnik (2018), Jepma \& Nieuwenhuis (2011), Katidioti, Borst \& Taatgen (2014), Oliva \& Anikin (2018), Berthold \& Slowiaczek (1975), Schneider et al. (2018), Lempert, Chen \& Fleming (2015), Lin et al. (2017), Satterthwaite et al. (2007), Brunyé \& Gardony (2017), Geng et al. (2015), Einhäuser, Koch \& Carter (2010), Fehrenbacher \& Djamasbi (2017), Prehn, Heekeren \& Van der Meer (2011), Porter et al. (2010), Rigato, Rieger \& Romei (2016), Schlemmer et al. (2005) and Mitra, McNeal \& Bondell (2017)

Bradley \& Janisse (1981), Dionisio et al. (2001), Seymour, Baker \& Gaunt (2013) and Webb et al. (2009)

Akdoğan, Balci \& Van Rijn (2016), Landgraf, Raisig \& Van Der Meer (2012), Nowack, Milfont \& Van der Meer (2013), Nuthmann \& Van der Meer (2005), Irons, Jeon \& Leber (2017), Kahneman, Onuska \& Wolman (1968), Moresi et al. (2008), Ribeiro \& Castelo-Branco (2019) and Massar et al. (2018)

Van Steenbergen \& Band (2013), D’Ascenzo et al. (2016) and Diede \& Bugg (2017)

Braem et al. (2015), Harsay et al. (2017), Raisig et al. (2007) and Raisig et al. (2010)

Juris \& Velden (1977), Reiner \& Gelfeld (2014) and Wright, Boot \& Morgan (2013)

Allard, Wadlinger \& Isaacowitz (2010), Blackburn \& Schirillo (2012), Bradley et al. (2008), Chiesa et al. (2015), Goldinger, He \& Papesh (2009), Kret et al. (2013), Lichtenstein-Vidne et al. (2017), Porter, Hood \& Troscianko (2006), Schrammel et al. (2009), Vanderhasselt et al. (2018), Wu, Laeng \& Magnussen (2012), Yrttiaho et al. (2017), Kret (2017) and Hammerschmidt et al. (2018)

Barlow (1969)

Elschner, Hübner \& Dambacher (2017), Hayes, Muday \& Schirillo (2013), Kuchinke et al. (2009), Powell \& Schirillo (2011), Schirillo (2014) and Alvarez et al. (2015)

Beall (1977)
Attenuated light reflex (Steinhauer, Condray \& Kasparek, 2000) 
Table 1 (continued)

\section{Pupillary Dilation}

Neutral versus emotional stimulus

tion

Sexual arousal
Bradley, Sapigao \& Lang (2017), Henderson, Bradley \& Lang (2017), Iijima et al. (2014), Chiew \& Braver (2014), Pearlstein et al. (2018), Thoma \& Baum (2018), Metalis \& Hess (1982), Babiker et al. (2015), Gingras et al. (2015), Laeng et al. (2016), Rosa et al. (2017), Widmann, Schröger \& Wetzel (2018), Park \& Whang (2018), Leuchs, Schneider \& Spoormaker (2018), Wollner, Hammerschmidt \& Albrecht (2018), Cohen, Moyal \& Henik (2015), Snowden et al. (2016), Urry et al. (2009), Vanderhasselt et al. (2014), Bebko et al. (2011), Bardeen \& Daniel (2017), Stanners et al. (1979), Kinner et al. (2017), Yih et al. (2018), Nunnally et al. (1967), Ferrari et al. (2016), Siegle et al. (2015), Damsma \& Van Rijn (2017), Kloosterman et al. (2015) and Bayer, Ruthmann \& Schacht (2017)

Aguillon-Hernandez et al. (2015) and Schneider et al. (2009)

Metalis \& Hess (1982), Dabbs (1997), Hamel (1974), Rieger \& SavinWilliams (2012) and Attard-johnson, Ciardha \& Bindemann (2018) of short term and working memory, e.g., recognizing previously presented words, pictures, or sounds (Brocher \& Graf, 2017; Brocher \& Graf, 2016; Gomes, Montaldi \& Mayes, 2015; Heaver \& Hutton, 2011; Johansson et al., 2018; Kafkas \& Montaldi, 2011; Kafkas \& Montaldi, 2015; Kafkas \& Montaldi, 2012; Mill, O’Connor \& Dobbins, 2016; Montefinese et al., 2013; Otero, Weekes \& Hutton, 2011; Bradley \& Lang, 2015; Herweg, Sommer \& Bunzeck, 2017; Võ et al., 2008; Weiss et al., 2016) or digit-recall tasks (Sher, 1971; Starc, Anticevic \& Repovš, 2017; Unsworth \& Robison, 2018b; Johnson, 1971; Klingner, Tversky \& Hanrahan, 2011; Taylor, 1981; Van Gerven et al., 2004; Wong \& Epps, 2016; Tsukahara, Harrison \& Engle, 2016; Bijleveld, 2018). Pupillary dilatation also reflects information storage and mental overload; memorizing more than five items evoked a pupillary dilatation lasting as long as the stimulus itself (Unsworth \& Robison, 2018b; Cabestrero, Crespo \& Quirós, 2009; Reinhard, Lachnit \& König, 2006). Of note, pupillary dilatation, recorded during an encoding-retrieval phase, is associated with activity in the ventral striatum and in the Globus pallidus as revealed by fMRI, suggesting involvement of these areas in memory formation and pupillary function (Herweg, Sommer \& Bunzeck, 2017).

Another mental process influencing pupillary diameter is attention, i.e., tasks such as reading and focusing on a target elicit pupillary dilatation. Attention related to the orienting reflex, e.g., associated with sudden noise or a bright stimulus, also elicits pupillary dilatation (Liao et al., 2016; Marois et al., 2018; Steiner \& Barry, 2011; Stelmack \& Siddle, 1982). Conversely, smaller pupil sizes are seen with mind-wandering and introspection, and decreasing pupillary diameters reflect distraction and poor task performance (Franklin et al., 2013; Hopstaken et al., 2016; Huijser, Van Vugt \& Taatgen, 2018; Smallwood et al., 2011; Unsworth \& Robison, 2016; Brink Van Den, Murphy \& Nieuwenhuis, 2016; Gouraud, Delorme \& Berberian, 2018a; Unsworth \& Robison, 2018a; Gouraud, Delorme \& Berberian, 2018b). Pupillary changes can thus uncover the level of attention and the amount of mental effort with high temporal resolution (Kang, Huffer \& Wheatley, 2014; Kang \& Wheatley, 2017; Wierda et al., 2012; Willems, Herdzin \& Martens, 2015). 
Based on the dilatation evoked by hearing and reading sentences, several authors assessed pupillary diameters to categorize language and word processing. Pupils dilate more with poor intelligibility (Koelewijn et al., 2012b; Winn, Edwards \& Litovsky, 2015; Zekveld, Kramer \& Festen, 2010; Zekveld, Festen \& Kramer, 2013; Zekveld et al., 2014a; Zekveld \& Kramer, 2014; Zekveld et al., 2014b) and increased effort for low compared to high frequency words (Kuchinke et al., 2007; Papesh \& Goldinger, 2012; Schmidtke, 2014), as well as for abstract compared to concrete words (Colman \& Paivio, 1970; Engelhardt, Ferreira \& Patsenko, 2010; Paivio \& Simpson, 1966; Simpson \& Paivio, 1968). Thus, pupillary dilatation reflects the amount of processing required for understanding of complex or ambiguous sentences (Ben-Nun, 1986; Schluroff et al., 1986; Tromp, Hagoort \& Meyer, 2016) and allow to explore differences between native and non-native speakers (Schmidtke, 2014; Borghini \& Hazan, 2018; Iacozza, Costa \& Duñabeitia, 2017).

Measuring the effectiveness of learning may also be monitored through pupillary dilatation. Learning processes such as Pavlovian, associative learning or categorization are characterized by large pupils initially, when the cognitive load is big, and by smaller diameters when the task or item is being learned (Reinhard, Lachnit \& König, 2006; Foroughi, Sibley \& Coyne, 2017; Shalev et al., 2018; Reinhard \& Lachnit, 2002; Van Der Meer et al., 2003; Kahya et al., 2018). Pupils also dilate in response to mental arithmetic (Steinhauer, Condray \& Kasparek, 2000; Bradshaw, 1967; Chen \& Epps, 2014; Marquart \& De Winter, 2015; Szulewski, Roth \& Howes, 2015; Szulewski et al., 2017; Steinhauer et al., 2004; Annerer-Walcher, Körner \& Benedek, 2018), decision-making and visual backward masking tasks (Verney, Granholm \& Dionisio, 2001; Verney, Granholm \& Marshall, 2004; Schneider et al., 2018; Wolffet al., 2015; Reilly et al., 2018; Trani \& Verhaeghen, 2018; Stojmenova \& Sodnik, 2018; Jepma \& Nieuwenhuis, 2011; Katidioti, Borst \& Taatgen, 2014; Oliva \& Anikin, 2018; Berthold \& Slowiaczek, 1975) and they can reveal the degree of certainty during any selection process, i.e., the more undecided one is, the greater the pupillary diameter (Lempert, Chen \& Fleming, 2015; Lin et al., 2017; Satterthwaite et al., 2007; Brunyé \& Gardony, 2017; Geng et al., 2015).

\section{Pupillary dilatation: emotions}

Stimuli causing emotional arousal can be revealed by changes in pupillary diameter. For instance, pupillary dilatation reflects preference for political candidates (Barlow, 1969), alcoholic beverages (Beall, 1977) and visual arts (e.g., Rembrandt's paintings) (Elschner, Hübner \& Dambacher, 2017; Hayes, Muday \& Schirillo, 2013; Kuchinke et al., 2009; Powell \& Schirillo, 2011; Schirillo, 2014; Alvarez et al., 2015) allowing to predict people's tastes. Images of human faces elicit a pupillary reaction as well: Angry or fearful facial expressions and images of females increase pupil sizes, in contrast to happy faces and males' images (Allard, Wadlinger \& Isaacowitz, 2010; Blackburn \& Schirillo, 2012; Bradley et al., 2008; Chiesa et al., 2015; Goldinger, He \& Papesh, 2009; Kret et al., 2013; Lichtenstein-Vidne et al., 2017; Porter, Hood \& Troscianko, 2006; Schrammel et al., 2009; Vanderhasselt et al., 2018; Wu, Laeng \& Magnussen, 2012; Yrttiaho et al., 2017; Kret, 2017; Hammerschmidt et al., 2018). Negative images showing violence, distress and threat but also positive ones depicting happiness elicited a dilatation as opposed to neutral everyday images (Henderson, 
Bradley \& Lang, 2014; Bradley, Sapigao \& Lang, 2017; Henderson, Bradley \& Lang, 2017; Iijima et al., 2014; Chiew \& Braver, 2014; Pearlstein et al., 2018; Thoma \& Baum, 2018). Pupillary dilatation may also signal the perception of odors (Aguillon-Hernandez et al., 2015; Schneider et al., 2009) and sexual arousal (Metalis \& Hess, 1982; Dabbs, 1997; Hamel, 1974; Rieger \& Savin-Williams, 2012; Attard-johnson, Ciardha \& Bindemann, 2018); salient odors or visual or auditory sexual stimuli lead to pupillary dilatation. Pupillary dilatation results also from pleasant sounds and melodies. Known music tracks enhance pupillary diameters but not unknown and less salient melodies (Babiker et al., 2015; Gingras et al., 2015; Laeng et al., 2016; Rosa et al., 2017; Widmann, Schröger \& Wetzel, 2018; Park \& Whang, 2018; Leuchs, Schneider \& Spoormaker, 2018; Wollner, Hammerschmidt \& Albrecht, 2018). Finally, measures of pupillary diameter may also reveal active mental efforts associated with coping strategies such as reappraisal or suppression of negative emotions (Cohen, Moyal \& Henik, 2015; Snowden et al., 2016; Urry et al., 2009; Vanderhasselt et al., 2014; Bebko et al., 2011; Bardeen \& Daniel, 2017; Stanners et al., 1979; Kinner et al., 2017; Yih et al., 2018). Neuroimaging studies involving fMRI show that at least some of these emotional conditions leading to pupillary dilatation are associated with increased activation of the amygdala, the ventro-medial prefrontal cortex (Brodmann areas 11 and 25), the lateral occipital complex (Kuniecki et al., 2018) and the dorsolateral prefrontal cortex (Brodmann areas 9 and 46) (Vanderhasselt et al., 2014).

\section{PICO 3: Pupillary changes associated with cortical stimulation and lesions in non-human primates}

Pupillary dilatation occurs in non-human primates in response to electrical stimulation of the frontal eye field (Brodmann area 8) during passive viewing tasks (Lehmann \& Corneil, 2016) ("probe in, probe out" conditions (Becket Ebitz \& Moore, 2017)), and of the superior colliculus (Wang et al., 2012; Joshi et al., 2016) during passive fixation tasks. One study compared non-human primates with amygdala lesions to healthy controls during a free viewing task; pupillary dilation was similar in both groups, but the pupillary light reflex was diminished in the lesion group (Dal Monte et al., 2015) (Table 2).

\section{PICO 4: Pupillary changes associated with cognitive and emotional activity in non-human primates}

As in humans, cognitive processes lead to pupillary dilatation in rhesus macaques. Changes in pupil diameters occur in non-human primates during different tasks such as button pushing (Iriki et al., 1996), visual orientation (Hampson, Opris \& Deadwyler, 2010; Ebitz, Pearson \& Platt, 2014), recognition and memory (Montefusco-Siegmund, Leonard \& Hoffman, 2017) or sensorial stimulation (e.g., auditory or electrodermal) (Joshi et al., 2016; Iriki et al., 1996). Some investigators correlated pupillary function with specific cortical or subcortical areas, recording neuronal firing through implanted electrodes. Neural activity during pupil dilatation was noted in the frontal cortex (Brodmann area 8) (Hampson, Opris $\&$ Deadwyler, 2010) and both anterior and posterior cingulate cortex (Brodmann areas 23, 24, 31, 32) (Joshi et al., 2016; Ebitz et al., 2015), as well as in key brainstem structures such as locus coeruleus and the inferior and superior colliculi (Joshi et al., 2016) (Table 3). 
Table 2 Non-human primate studies on the relationship of pupillary function with specific cortical/subcortical structures. List of studies investigating if micro stimulation of some cerebral areas, through previously implanted electrodes, resulted in pupillary changes in diameter.

\begin{tabular}{|c|c|c|c|c|c|c|}
\hline Source & Species & $\begin{array}{l}\text { Pupillary } \\
\text { assessment }\end{array}$ & $\begin{array}{l}\text { Stimulated } \\
\text { areas }\end{array}$ & Task & $\begin{array}{l}\text { Pupillary } \\
\text { dilation }\end{array}$ & $\begin{array}{l}\text { Pupillary re- } \\
\text { sponses other } \\
\text { than dilation }\end{array}$ \\
\hline \multirow[t]{2}{*}{$\begin{array}{l}\text { Becket Ebitz \& } \\
\text { Moore (2017) }\end{array}$} & $\begin{array}{l}\text { Rhesus } \\
\text { Macaque } \\
(n=2)\end{array}$ & $\begin{array}{l}\text { Eyelink } \\
1000 \text { (SR } \\
\text { Research) }\end{array}$ & $\begin{array}{l}\text { Frontal Eye } \\
\text { Field (Area } \\
8 \text { ) }\end{array}$ & $\begin{array}{l}\text { Fixation (with } \\
\text { distraction) }\end{array}$ & None & $\begin{array}{l}\text { Enhanced } \\
\text { pupillary light } \\
\text { reflex }\end{array}$ \\
\hline & & & & $\begin{array}{l}\text { Fixation (with- } \\
\text { out distrac- } \\
\text { tion) }\end{array}$ & Yes & \\
\hline \multirow[t]{3}{*}{$\begin{array}{l}\text { Joshi et al. } \\
\text { (2016) }\end{array}$} & $\begin{array}{l}\text { Rhesus } \\
\text { Macaque } \\
(n=5)\end{array}$ & $\begin{array}{l}\text { Eyelink } \\
1000 \text { (SR } \\
\text { Research) }\end{array}$ & $\begin{array}{l}\text { Locus } \\
\text { Coeruleus }\end{array}$ & None & Yes & None \\
\hline & & & $\begin{array}{l}\text { Inferior } \\
\text { Colliculus }\end{array}$ & & & \\
\hline & & & $\begin{array}{l}\text { Superior } \\
\text { Colliculus }\end{array}$ & & & \\
\hline $\begin{array}{l}\text { Lehmann \& } \\
\text { Corneil (2016) }\end{array}$ & $\begin{array}{l}\text { Rhesus } \\
\text { Macaque } \\
(n=2)\end{array}$ & $\begin{array}{l}\text { ETL } 200 \text { (IS- } \\
\text { can) }\end{array}$ & $\begin{array}{l}\text { Frontal Eye } \\
\text { Field (Area } \\
8 \text { ) }\end{array}$ & Fixation & Yes & None \\
\hline $\begin{array}{l}\text { Wang et al. } \\
\text { (2012) }\end{array}$ & $\begin{array}{l}\text { Rhesus } \\
\text { Macaque } \\
(n=2)\end{array}$ & $\begin{array}{l}\text { Eyelink } \\
\text { II (SR } \\
\text { Research) }\end{array}$ & $\begin{array}{l}\text { Superior } \\
\text { Colliculus }\end{array}$ & Fixation & Yes & None \\
\hline \multirow[t]{2}{*}{ Jampel (1960) } & $\begin{array}{l}\text { Rhesus } \\
\text { Macaque } \\
(n=9)\end{array}$ & $\begin{array}{l}\text { Visual in- } \\
\text { spection }\end{array}$ & $\begin{array}{l}\text { Frontal } \\
\text { Cortex } \\
\text { (Area 8-9- } \\
10)\end{array}$ & None & Yes & $\begin{array}{l}\text { Pupillary con- } \\
\text { striction and } \\
\text { accomodation }\end{array}$ \\
\hline & & & $\begin{array}{l}\text { Occipital } \\
\text { Cortex } \\
\text { (Area 18- } \\
19-22)\end{array}$ & & & \\
\hline $\begin{array}{l}\text { Dal Monte } \\
\text { et al. (2015) }\end{array}$ & $\begin{array}{l}\text { Rhesus } \\
\text { Macaque } \\
(n=8)\end{array}$ & $\begin{array}{l}\text { Arrington } \\
\text { View Point }\end{array}$ & $\begin{array}{l}{ }^{a} \text { Amygdala } \\
\text { lesions }\end{array}$ & Free viewing & Yes & $\begin{array}{l}\text { Reduction of } \\
\text { pupillary light } \\
\text { reflex }\end{array}$ \\
\hline
\end{tabular}

Notes.

${ }^{\mathrm{a} C}$ Comparison between monkeys with amygdala lesions and healthy controls.

\section{DISCUSSION}

This systematic review reveals that pupils do not only dilate and constrict in response to light, but a large number of cognitive and emotional processes affects pupillary function and leads to pupillary dilatation and, less often, to constriction (Table 1). Pupil diameter may serve as an index of brain activity, reflecting mental efforts (or lack of efforts). Thus, our pupils dilate, when we are focused in contrast to when we let our minds wander; they dilate when we are dishonest and lying; when we enjoy or dislike what we are seeing; and when we are engaged in learning and processing of information.

\section{Pupillary dilatation}

The most commonly observed response following emotional or cognitive tasks is pupillary dilatation. In humans, as well as in non-human primates, this is due to sympathetic 
Table 3 Non-human primate studies on the relationship of cognitive and emotional processes with pupillary function and activation of cortical/subcortical areas. Characteristics of studies investigating which tasks and/or sensorial stimulus evoked a pupillary response and which cerebral areas were simultaneously activated.

\begin{tabular}{|c|c|c|c|c|c|c|c|}
\hline Source & Species & $\begin{array}{l}\text { Pupillary assess- } \\
\text { ment }\end{array}$ & $\begin{array}{l}\text { Cortical and subcortical Recorded } \\
\text { activity }\end{array}$ & Cognitive task & $\begin{array}{l}\text { Sensory stim- } \\
\text { ulus }\end{array}$ & $\begin{array}{l}\text { Pupillary di- } \\
\text { lation }\end{array}$ & $\begin{array}{l}\text { Pupillary re- } \\
\text { sponses other } \\
\text { than dilation }\end{array}$ \\
\hline $\begin{array}{l}\text { Hampson, Opris \& } \\
\text { Deadwyler (2010) }\end{array}$ & $\begin{array}{l}\text { Rhesus Macaque } \\
(n=4)\end{array}$ & $\begin{array}{l}\text { EyeLink } 1000 \text { (SR } \\
\text { Research) }\end{array}$ & Frontal Cortex (Area 8) & $\begin{array}{l}\text { Visual Delayed } \\
\text { Match to Sam- } \\
\text { ple }\end{array}$ & N/A & Yes & None \\
\hline Iriki et al. (1996) & $\begin{array}{l}\text { Japanese } \\
\text { Macaque }(n=2)\end{array}$ & $\begin{array}{l}\text { MOS camera un- } \\
\text { der infrared illumi- } \\
\text { nation }\end{array}$ & $\begin{array}{l}\text { Somatosensory Cortex (Area 3, Post- } \\
\text { central Gyrus, finger hand region) }\end{array}$ & $\begin{array}{l}\text { Button Pushing } \\
\text { N/A }\end{array}$ & $\begin{array}{l}\text { N/A } \\
\text { Passive Skin } \\
\text { Stimulation }\end{array}$ & $\begin{array}{l}\text { Yes } \\
\text { No }\end{array}$ & $\begin{array}{l}\text { None } \\
\text { None }\end{array}$ \\
\hline Joshi et al. (2016) & $\begin{array}{l}\text { Rhesus Macaque } \\
(n=5)\end{array}$ & $\begin{array}{l}\text { EyeLink } 1000 \text { (SR } \\
\text { Research) }\end{array}$ & $\begin{array}{l}\text { Locus Coeruleus Inferior and Supe- } \\
\text { rior Colliculus, Anterior and Poste- } \\
\text { rior Cingulate Cortex (Areas 32, } 23 \\
\text { and 31) }\end{array}$ & a & $\begin{array}{l}\text { N/A } \\
\text { Startling } \\
\text { Tone }\end{array}$ & $\begin{array}{l}\text { Yes } \\
\text { Yes }\end{array}$ & $\begin{array}{l}\text { Oscillations } \\
\text { None }\end{array}$ \\
\hline $\begin{array}{l}\text { Montefusco- } \\
\text { Siegmund, Leonard e } \\
\text { Hoffman (2017) }\end{array}$ & $\begin{array}{l}\text { Rhesus Macaque } \\
(n=2)\end{array}$ & $\begin{array}{l}\text { iViewX Hi-Speed } \\
\text { (SBI) }\end{array}$ & Hippocampus & $\begin{array}{l}\text { Visual Search } \\
\text { and Detection } \\
\text { N/A }\end{array}$ & $\begin{array}{l}\text { N/A } \\
\text { Visual pre- } \\
\text { sentation of } \\
\text { natural scenes }\end{array}$ & Yes & None \\
\hline Ebitz et al. (2015) & $\begin{array}{l}\text { Rhesus Macaque } \\
(n=2)\end{array}$ & $\begin{array}{l}\text { EyeLink } 1000 \text { (SR } \\
\text { Research) }\end{array}$ & $\begin{array}{l}\text { Dorsal Anterior Cingulate Cortex } \\
\text { (Area 24) }\end{array}$ & $\begin{array}{l}\text { Task Conflict } \\
\text { and Error }\end{array}$ & N/A & N/A & $\begin{array}{l}\text { Differences in } \\
\text { pupils' baselines }\end{array}$ \\
\hline $\begin{array}{l}\text { Ebitz, Pearson \& } \\
\text { Platt (2014) }\end{array}$ & $\begin{array}{l}\text { Rhesus Macaque } \\
(n=4)\end{array}$ & $\begin{array}{l}\text { EyeLink } 1000 \text { (SR } \\
\text { Research) }\end{array}$ & N/A & $\begin{array}{l}\text { Visual Orient- } \\
\text { ing With Dis- } \\
\text { tractors }\end{array}$ & N/A & N/A & $\begin{array}{l}\text { Differences in } \\
\text { pupils' baselines }\end{array}$ \\
\hline $\begin{array}{l}\text { Cash-Padgett et al. } \\
\text { (2018) }\end{array}$ & $\begin{array}{l}\text { Rhesus Macaque } \\
(n=2)\end{array}$ & $\begin{array}{l}\text { EyeLink } 1000 \text { (SR } \\
\text { Research) }\end{array}$ & $\begin{array}{l}\text { Dorsal and Subgenual Anterior Cin- } \\
\text { gulate (Areas 24,33) }\end{array}$ & $\begin{array}{l}\text { Decision mak- } \\
\text { ing (gambling } \\
\text { task) }\end{array}$ & N/A & Yes & None \\
\hline
\end{tabular}

Notes.

${ }^{\mathrm{a}}$ No cognitive task required, only fixation. 
activation or parasympathetic inhibition or a combination of the two (Steinhauer, Condray $\&$ Kasparek, 2000) and based on unconscious mechanisms. Hence, tasks that require a high amount of attention such as memory retrieval, mental arithmetic or language processing elicit a sympathetic activation. Similarly, emotional sounds and images induce a state of arousal, which involves sympathetic activity leading to pupillary dilatation.

Cerebral structures involved in vigilance, arousal and attention and responsible for changes in pupillary diameter during cognitive and emotional processes include the locus coeruleus (Joshi et al., 2016; Murphy et al., 2014), the superior colliculus (Wang et al., 2012) and multiple regions of the frontal/prefrontal cortex (Brodmann areas 8, 9 and 11 ) (Becket Ebitz \& Moore, 2017; Lehmann \& Corneil, 2016) (Fig. 2). Of these, the locus coeruleus seems to be the most influential mediator of the pupillary light reflex. This pontine nucleus is part of the ascending reticular activating system (ARAS) and intimately and reciprocally linked to the orbitofrontal cortex (Brodmann area 11) and the anterior cingulate cortex (Brodmann area 24 and 32) (Johansson et al., 2018; Geva et al., 2013) which are both fundamental to motivational relevance and target fixation. Evidence from studies of these networks supports the notion that attention and vigilance are related to the regulation of pupillary light reflex. Thus, the locus coeruleus modulates an excitatory connection to the sympathetic network of the pupil (in particular to the intermediate-medial-lateral cell column of the spinal cord) and an inhibitory connection to the parasympathetic pathway (directing to the Edinger Westphal nucleus). Activation of the locus coeruleus leads to increased sympathetic and decreased parasympathetic activity and, consequently, pupil dilatation (Samuels \& Szabadi, 2008). Two recent studies highlight these aspects. According to Joshi et al. (2016), the locus coeruleus acts together with the inferior and superior colliculi, as well as the anterior and posterior cingulate cortex (Brodmann areas 23, 24, 31,32) likely in response to increased vigilance and alertness, thereby modifying the pupillary diameter. The second study (Schneider et al., 2016), conducted on human beings, confirms this theory and shows that, based on data from resting state magnetic resonance imaging, pupil dilatation is related to an increased activity of the thalamus and frontoparietal regions (Brodmann areas 6, 39, 40), involved in the so-called tonic alert status and vigilance, and to increased metabolism of the visual and sensory-motor regions.

Besides the locus coeruleus, the superior colliculus seems to play a key role in modulating the pupillary light reflex. Wang et al. (2012) reported that pupils temporarily dilate after stimulation of the intermediate layer of the superior colliculus in non-human primates. Further, Mill, O'Connor \& Dobbins (2016) and Herweg, Sommer \& Bunzeck (2017) suggested that the superior colliculus receives neuronal inputs from temporal, frontal and parietal areas and basal ganglia, especially striatal and pallidal neuronal groups, leading to pupillary dilatation associated with memory tasks.

In addition, different experimental conditions in macaques show that stimulation of the frontal eye field (Brodmann area 8) might modulate the pupillary light reflex (Becket Ebitz \& Moore, 2017; Hampson, Opris \& Deadwyler, 2010). For instance, simultaneous micro-stimulations of the frontal eye field and of pretectum structures enhance the activity of frontal eye field neurons with similar spatial tuning and reduce, or 


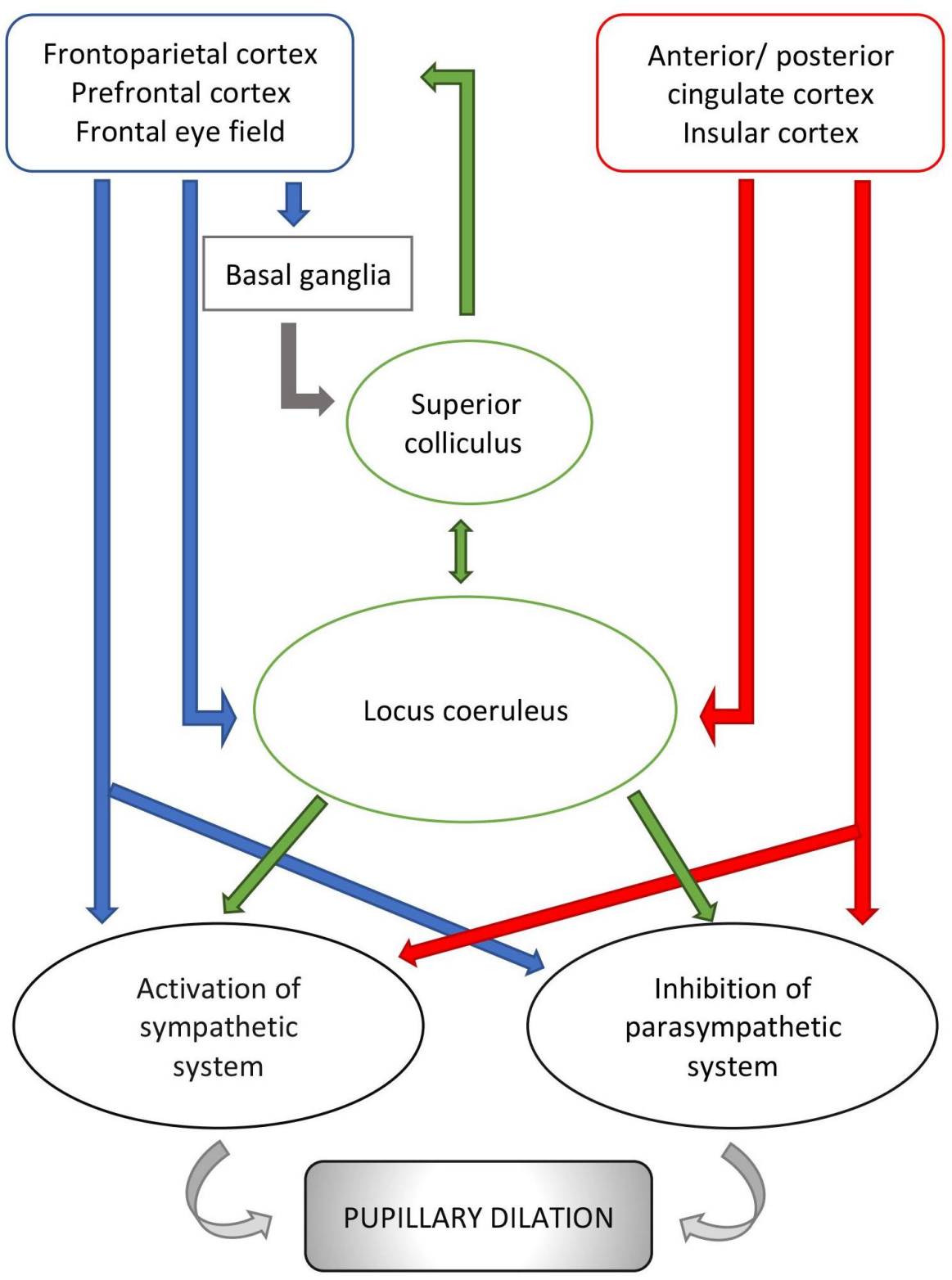

Figure 2 Schematic representation of pupillary pathways that are activated during cognitive and emotional processes, including arousal and vigilance. Pathways, connecting the cortical areas to the parasympathetic system and the sympathetic system, are inhibitory or activating. Neurons emerging from the locus coeruleus inhibit the parasympathetic system at the Edinger Westphal nucleus and activate the sympathetic system via connection to the spinal cord tract of the sympathetic system. Red arrows: connections from cortical areas involved in the autonomic control i.e., anterior/posterior cingulate cortex and insular cortex. Blue arrows: connections from other cortical areas involved in visual processes. Green arrows: connections from subcortical structures i.e., locus coeruleus and superior colliculus. For reference to Brodmann areas, see text.

Full-size DOI: 10.7717/peerj.6882/fig-2 
even suppress, the activity of neurons with different tuning (Schlag, Dassonville \& SchlagRey, 1998). From these observations, Becket Ebitz \& Moore (2017) hypothesized that the frontal eye field and parts of the pretectum interact in regulating pupillary function.

Although evaluation of the pupils is part of the routine clinical examination, only few human studies have correlated pupillary function with specific cerebral areas to replicate results from (invasive) non-human primate studies. Systematic studies on pupil diameter have been conducted in three clinical settings: Raised intracranial pressure, which may lead to oculomotor nerve compression and brain herniation; traumatic brain injury and cerebrovascular disease; but only studies on the latter have provided data on candidate cerebral areas that may regulate the pupillary light reflex. The classical work on this topic is by Herman (1975). In a retrospective study of 363 cerebral infarction patients, having excluded previous ocular pathology, local trauma, and active blood serology, the author reported that $5 \%$ of the examined patients had an asymmetrical pupillary response. Among the patients with pupillary asymmetry, $80 \%$ showed contralateral hemispheric stroke lesions, associated with other focal neurological signs and $20 \%$ of the patients had a dilated pupil homolaterally to the hemispheric lesion. A more recent work (Peinkhofer et al., 2018) found differences in the second phase of the pupillary light reflex, i.e., when pupils dilate back to baseline diameter, in patients with prefrontal eye field and/or insular infarcts (Brodmann areas 8, 13 and 16). In this study the authors assessed pupillary function in patients with an acute anterior circulation stroke, treated with endovascular thrombectomy, and compared patients with infarcts in the prefrontal eye field and/or insular cortex to patients with infarcts in other areas (based on neuroimaging). No difference was found in the overall pupillary function, but subtle changes were observed in the dilatation phase. Therefore, the prefrontal eye field and/or insular cortex may have a role in modulation of pupillary light reflex, influencing the autonomic system directly or indirectly, perhaps via connections to subcortical structures such as the locus coeruleus. Similarly, it seems that subjects with focal damage in ventral and medial prefrontal cortex (Brodmann areas 11 and 25) have a constant reduction of reward-induced autonomic pupil responses, compared to age-matched, healthy controls, confirming the involvement of these areas in the cortical modulation of pupillary light reflex (Manohar et al., 2016).

\section{Pupillary constriction}

Pupillary constriction, induced by the parasympathetic system, is less frequently associated with cognitive or emotional processes than pupillary dilatation. It can be related to parasympathetic eliciting emotions such as disgust (Ayzenberg, Hickey \& Lourenco, 2018) or memory tasks (Naber et al., 2013). The latter result is in contrast to the great majority of the studies on this topic (Kafkas \& Montaldi, 2015; Kafkas \& Montaldi, 2012; Bradley $\&$ Lang, 2015) that reveal pupillary dilatation but the difference seems to be mainly methodological, that is, related to the temporal evolution of the pupillary reflects analyzed: the first phase (i.e., constriction) or the second phase (i.e., dilatation), which are present in any task involving visual information processing.

Of course, pupillary constriction is mostly related to light stimuli. However, constriction following bright stimuli seems to go beyond the simple brainstem oculomotor 
reflex (Steinhauer, Condray \& Kasparek, 2000; Henderson, Bradley \& Lang, 2017). For instance, subjects presented with half bright-half dark objects showed pupillary constriction when focusing on the bright side as opposed to dilatation when switching attention towards the darker side, suggesting that pupillary function depends more on the attended stimulus than on the amount of light (Mathôt et al., 2014; Binda, Pereverzeva \& Murray, 2013a; Binda, Pereverzeva \& Murray, 2014; Binda \& Murray, 2015; Mathôt et al., 2013; Mathôt et al., 2016; Naber, Alvarez \& Nakayama, 2013). Constriction was also observed with illusory images of brightness (Laeng \& Endestad, 2012), with mental representation associated to light such as "sunny skies" (Laeng \& Sulutvedt, 2014) and with written or spoken words such as "lamp", suggesting the presence of cortical influence of the brainstem light reflex pathway. Furthermore seeing intact images of the sun as opposed to scrambled images elicited a constriction (Naber \& Nakayama, 2013; Sperandio, Bond \& Binda, 2018; Binda, Pereverzeva \& Murray, 2013b). Pupillary reaction influenced by images (Laeng $\&$ Sulutvedt, 2014), ambiguous stimulation (Turi, Burr \& Binda, 2018) or memory tasks (Blom et al., 2016) has been suggested as tool to test subjective perception (Turi, Burr \& Binda, 2018; Laeng \& Sulutvedt, 2014; Mathôt, Grainger \& Strijkers, 2017). In addition, experimental evidence for cortical control of the light reflex was provided by Becket Ebitz \& Moore (2017).

\section{Neuronal pathways}

In light of these findings, the circuit behind pupillary function involves neuronal pathways connecting cortical regions to the locus coeruleus and the superior colliculus, two main pretectum structures. The locus coeruleus receives signals from the insular cortex (Brodmann areas 13 and 16), the anterior and posterior cingulate cortex (Brodmann areas $23,24,31,32$ ) and prefrontal cortex (Brodmann area 9, 11, 25). The superior colliculus receives inputs from frontal (Brodmann area 8 ), and frontoparietal cortex (Brodmann areas $6,39,40)$. Of note, Brodmann areas $6,8,39$ and 40 might be connected to the locus coeruleus directly and indirectly via areas 13, 16, 23, 24, 31 and 32 (Mill, O'Connor \& Dobbins, 2016; Lehmann \& Corneil, 2016; Wang et al., 2012; Joshi et al., 2016; Alnaes et al., 2014). The locus coeruleus projects directly, and indirectly via the paragigantocellularis nucleus of the ventral medulla, to the Edinger-Westphal nucleus (Joshi et al., 2016). Similarly, the superior colliculus sends inputs directly, and indirectly via the mesencephalic cuneiform nucleus, to the Edinger-Westphal nucleus (Wang et al., 2012). However, there also exist pathways that connect the locus coeruleus with the superior colliculus directly (Lehmann \& Corneil, 2016).

\section{Limitations}

It should be noted that this systematic review has some limitations. First, we excluded studies with less than 15 patients, perhaps missing some relevant research. Second, the tools used to measure pupillary function were not the same across studies and, third, the exclusion criteria regarding previous neurological or ocular pathologies were not always clearly stated. Finally, it should be noted that pupillary function can be influenced by medication affecting the noradrenergic system, and very few papers provided information 
about the presence of absence of such medication. On the positive side, this paper is the only recent review on the topic and includes more than 200 publications on cortical pathways and behaviors modulating pupillary function.

In summary, this review shows that:

- cognitive efforts and processing of emotional stimuli influence pupillary diameter in both humans and rhesus macaques, typically evoking pupillary dilatation;

- pupillary constriction occurs in response to light stimuli, both real and imagined, suggesting a cortical influence on subcortical reflex pathway;

- damage to salient cortical and subcortical areas such as frontal and prefrontal cortex, as well as key structures for autonomic control, seem to affect pupillary function by modulating the pupillary diameter;

- and micro stimulation of the frontal eye field (Brodmann area 8), locus coeruleus and superior colliculus in non-human primates leads to pupillary dilatation, suggesting involvement of these areas in the pupillary light reflex.

\section{CONCLUSIONS}

Cognitive and emotional processes evoke a change in pupillary diameter, typically dilatation, in both humans and non-human primates, reflecting vigilance, arousal or attention. Stimuli related to light, whether real or imagined, elicit a pupillary constriction. Both dilatation and constriction are dependent on autonomic activation with cortical influence. The main structures involved are the locus coeruleus and the superior colliculus because of their direct and indirect connections to the Edinger-Westphal nucleus. Furthermore, cortical areas such as the prefrontal and the frontal cortex, particularly the frontal eye field (Brodmann area 8) and areas involved in autonomic control, such as insular cortex (Brodmann areas 13 and 16) and anterior cingulate cortex (Brodmann areas 24 and 32), modulate the pupillary light reflex via connections to subcortical structures and the Edinger-Westphal nucleus.

\section{ADDITIONAL INFORMATION AND DECLARATIONS}

\section{Funding}

The authors received no funding for this work.

\section{Competing Interests}

The authors declare there are no competing interests.

\section{Author Contributions}

- Costanza Peinkhofer performed the experiments, analyzed the data, contributed reagents/materials/analysis tools, prepared figures and/or tables, authored or reviewed drafts of the paper, approved the final draft.

- Gitte M. Knudsen authored or reviewed drafts of the paper, approved the final draft. 
- Rita Moretti performed the experiments, analyzed the data, contributed reagents/materials/analysis tools, authored or reviewed drafts of the paper, approved the final draft.

- Daniel Kondziella conceived and designed the experiments, performed the experiments, analyzed the data, contributed reagents/materials/analysis tools, prepared figures and/or tables, authored or reviewed drafts of the paper, approved the final draft.

\section{Data Availability}

The following information was supplied regarding data availability:

No raw data were generated; this is a systematic review.

\section{Supplemental Information}

Supplemental information for this article can be found online at http://dx.doi.org/10.7717/ peerj.6882\#supplemental-information.

\section{REFERENCES}

Aguillon-Hernandez N, Naudin M, Roché L, Bonnet-Brilhault F, Belzung C, Martineau J, Atanasova B. 2015. An odor identification approach based on event-related pupil dilation and gaze focus. International Journal of Psychophysiology 96(3):201-209 DOI 10.1016/j.ijpsycho.2015.03.009.

Akdoğan B, Balci F, Van Rijn H. 2016. Temporal expectation indexed by pupillary response. Timing and Time Perception 4(4):354-370 DOI 10.1163/22134468-00002075.

Allard ES, Wadlinger HA, Isaacowitz DM. 2010. Positive gaze preferences in older adults: assessing the role of cognitive effort with pupil dilation. Aging, Neuropsychology, and Cognition 17(3):296-311 DOI 10.1080/13825580903265681.

Alnaes D, Sneve MH, Espeseth T, Endestad T, Van de Pavert SHP, Laeng B. 2014. Pupil size signals mental effort deployed during multiple object tracking and predicts brain activity in the dorsal attention network and the locus coeruleus. Journal of Vision 14(4):1 DOI 10.1167/14.4.1.

Alvarez SA, Winner E, Hawley-Dolan A, Snapper L. 2015. What gaze fixation and pupil dilation can tell us about perceived differences between abstract art by artists versus by children and animals. Perception 44(11):1310-1331 DOI 10.1177/0301006615596899.

Annerer-Walcher S, Körner C, Benedek M. 2018. Eye behavior does not adapt to expected visual distraction during internally directed cognition. PLOS ONE 13(9):e0204963 DOI 10.1371/journal.pone.0204963.

Ariel R, Castel AD. 2014. Eyes wide open: enhanced pupil dilation when selectively studying important information. Experimental Brain Research 232(1):337-344 DOI 10.1007/s00221-013-3744-5.

Attard-johnson J, Ciardha CÓ, Bindemann M. 2018. Comparing methods for the analysis of pupillary response. Behavior Research Methods 51(1):83-95 DOI 10.3758/s13428-018-1108-6. 
Ayzenberg V, Hickey MR, Lourenco SF. 2018. Pupillometry reveals the physiological underpinnings of the aversion to holes. PeerJ 6:e4185 DOI 10.7717/peerj.4185.

Babiker A, Faye I, Prehn K, Malik A. 2015. Machine learning to differentiate between positive and negative emotions using pupil diameter. Frontiers in Psychology 6:Article 1921 DOI 10.3389/fpsyg.2015.01921.

Bakes A, Bradshaw CM, Szabadi E. 1990. Diminished pupillary light reflex in anxiety disorder. British Journal of Clinical Pharmacology 29(5):590-591.

Bardeen JR, Daniel TA. 2017. An eye-tracking examination of emotion regulation, attentional bias, and pupillary response to threat stimuli. Cognitive Therapy and Research 41(6):853-866 DOI 10.1007/s10608-017-9860-y.

Barlow JD. 1969. Pupillary size as an index of preference in political candidates. Perceptual and Motor Skills 28(2):587-590 DOI 10.2466/pms.1969.28.2.587.

Bayer M, Ruthmann K, Schacht A. 2017. The impact of personal relevance on emotion processing: evidence from event-related potentials and pupillary responses. Social Cognitive and Affective Neuroscience 12(9):1470-1479 DOI 10.1093/scan/nsx075.

Bayer M, Sommer W, Schacht A. 2011. Emotional words impact the mind but not the body: evidence from pupillary responses. Psychophysiology 48(11):1554-1562 DOI 10.1111/j.1469-8986.2011.01219.

Beall S. 1977. Pupillary responses as a measure of attitudes about alcoholic beverages. Perceptual and Motor Skills 45(3):751-756 DOI 10.2466/pms.1977.45.3.751.

Beatty J, Wagoner BL. 1978. Pupillometric signs of brain activation vary with level of cognitive processing. Science 199(4334):1216-1218.

Bebko GM, Franconeri SL, Ochsner KN, Chiao JY. 2011. Look before you regulate: differential perceptual strategies underlying expressive suppression and cognitive reappraisal. Emotion 11(4):732-742 DOI 10.1037/a0024009.

Becket Ebitz R, Moore T. 2017. Selective modulation of the pupil light reflex by microstimulation of prefrontal cortex. Journal of Neuroscience 37(19):5008-5018 DOI 10.1523/JNEUROSCI.2433-16.2017.

Ben-Nun Y. 1986. The use of pupillometry in the study of on-line verbal processing: evidence for depths of processing. Brain and Language 28(1):1-11 DOI 10.1016/0093-934X(86)90086-6.

Bergt A, Urai AE, Donner TH, Schwabe L. 2018. Reading memory formation from the eyes. European Journal of Neuroscience 47(12):1525-1533 DOI 10.1111/ejn.13984.

Berthold HC, Slowiaczek ML. 1975. Visual significance of pupillary response to an auditory task. Perceptual and Motor Skills 41(3):821-822 DOI 10.2466/pms.1975.41.3.821.

Bijleveld E. 2018. The feeling of effort during mental activity. Consciousness and Cognition 63:218-227 DOI 10.1016/j.concog.2018.05.013.

Binda P, Murray SO. 2015. Spatial attention increases the pupillary response to light changes. Journal of Vision 15(2):Article 1 DOI 10.1167/15.2.1.

Binda P, Pereverzeva M, Murray SO. 2013a. Attention to bright surfaces enhances the pupillary light reflex. Journal of Neuroscience 33(5):2199-2204 DOI 10.1523/JNEUROSCI.3440-12.2013. 
Binda P, Pereverzeva M, Murray SO. 2013b. Pupil constrictions to photographs of the sun. Journal of Vision 13(6):8 DOI 10.1167/13.6.8.

Binda P, Pereverzeva M, Murray SO. 2014. Pupil size reflects the focus of feature-based attention. Journal of Neurophysiology 112(12):3046-3052 DOI 10.1152/jn.00502.2014.

Bittner DM, Wieseler I, Wilhelm H, Riepe MW, Müller NG. 2014. Repetitive pupil light reflex: potential marker in alzheimer's disease? Journal of Alzheimer's Disease 42(4):1469-1477 DOI 10.3233/JAD-140969.

Blackburn K, Schirillo J. 2012. Emotive hemispheric differences measured in real-life portraits using pupil diameter and subjective aesthetic preferences. Experimental Brain Research 219(4):447-455 DOI 10.1007/s00221-012-3091.

Blom T, Mathôt S, Olivers CNL, Van der Stigchel S. 2016. The pupillary light response reflects encoding, but not maintenance, in visual working memory. Journal of Experimental Psychology: Human Perception and Performance 42(11):1716-1723 DOI 10.1037/xhp0000252.

Borghini G, Hazan V. 2018. Listening effort during sentence processing is increased for non-native listeners: a pupillometry study. Frontiers in Neuroscience 12:Article 152 DOI 10.3389/fnins.2018.00152.

Boyer S, Paubel PV, Ruiz R, Yagoubi REl, Daurat A. 2018. Human voice as a mesaure of mental load. Journal of Speech, Language, and Hearing Research 61(11):2722-2734 DOI 10.1016/0093-934X(86)90086-6.

Bradley MT, Janisse MP. 1981. Accuracy demonstrations, threat, and the detection of deception: cardiovascular, electrodermal, and pupillary measures. Psychophysiology 18(3):307-315 DOI 10.1111/j.1469-8986.1981.tb03040.

Bradley MM, Lang PJ. 2015. Memory, emotion, and pupil diameter: repetition of natural scenes. Psychophysiology 52(9):1186-1193 DOI 10.1111/psyp.12442.

Bradley MM, Miccoli L, Escrig MA, Lang PJ. 2008. The pupil as a measure of emotional arousal and autonomic activation. Psychophysiology 45(4):602-607 DOI 10.1111/j.1469-8986.2008.00654.

Bradley MM, Sapigao RG, Lang PJ. 2017. Sympathetic ANS modulation of pupil diameter in emotional scene perception: effects of hedonic content, brightness, and contrast. Psychophysiology 54(10):1419-1435 DOI 10.1111/psyp.12890.

Bradshaw J. 1967. Pupil size as a measure of arousal during information processing (Klingner, Tversky \& Hanrahan, 2011). Nature 216(5114):515-516 DOI 10.1038/216515a0.

Braem S, Coenen E, Bombeke K, Van Bochove ME, Notebaert W. 2015. Open your eyes for prediction errors. Cognitive, Affective, \& Behavioral Neuroscience 15(2):374-380 DOI 10.3758/s13415-014-0333-4.

Brink Van Den RL, Murphy PR, Nieuwenhuis S. 2016. Pupil diameter tracks lapses of attention. PLOS ONE 11(10):e0165274 DOI 10.1371/journal.pone.0165274.

Brocher A, Graf T. 2016. Pupil old/new effects reflect stimulus encoding and decoding in short-term memory. Psychophysiology 53(12):1823-1835 DOI 10.1111/psyp.12770. 
Brocher A, Graf T. 2017. Decision-related factors in pupil old/new effects: attention, response execution, and false memory. Neuropsychologia 102:124-134 DOI 10.1016/j.neuropsychologia.2017.06.011.

Brocher A, Harbecke R, Graf T, Memmert D, Hüttermann S. 2018. Using task effort and pupil size to track covert shifts of visual attention independently of a pupillary light reflex. Behavior Research Methods 50(6):2551-2567 DOI 10.3758/s13428-018-1033-8.

Brunyé TT, Gardony AL. 2017. Eye tracking measures of uncertainty during perceptual decision making. International Journal of Psychophysiology 120:60-68 DOI 10.1016/j.ijpsycho.2017.07.008.

Cabestrero R, Crespo A, Quirós P. 2009. Pupillary dilation as an index of task demands. Perceptual and Motor Skills 109(3):664-678 DOI 10.2466/pms.109.3.664-678.

Campbell MJ, Toth AJ, Brady N. 2018. Illuminating sex differences in mental rotation using pupillometry. Biological Psychology 138:19-26 DOI 10.1016/j.biopsycho.2018.08.003.

Carver RP. 1971. Pupil dilation and its relationship to information processing during reading and listening. Journal of Applied Psychology 55(2):126-134 DOI 10.1037/h0030664.

Cash-Padgett T, Azab H, Yoo SBM, Hayden BY. 2018. Opposing pupil responses to offered and anticipated reward values. Animal Cognition 21(5):671-684 DOI 10.1007/s10071-018-1202-2.

Causse M, Sénard JM, Démonet JF, Pastor J. 2010. Monitoring cognitive and emotional processes through pupil and cardiac response during dynamic versus logical task. Appl Psychophysiol Biofeedback 35(2):115-123 DOI 10.1007/s10484-009-9115-0.

Chatham CH, Claus ED, Kim A, Curran T, Banich MT, Munakata Y. 2012. Cognitive control reflects context monitoring, not motoric stopping, in response inhibition. PLOS ONE 7(2):e31546 DOI 10.1371/journal.pone.0031546.

Chen S, Epps J. 2014. Using task-induced pupil diameter and blink rate to infer cognitive load. Human-Computer Interact 29(4):390-413 DOI 10.1080/07370024.2014.892428.

Chiesa PA, Liuzza MT, Acciarino A, Aglioti SM. 2015. Subliminal perception of others' physical pain and pleasure. Experimental Brain Research 233(8):2373-2382 DOI 10.1007/s00221-015-4307-8.

Chiew KS, Braver TS. 2013. Temporal dynamics of motivation-cognitive control interactions revealed by high-resolution pupillometry. Frontiers in Psychology 4:Article 15 DOI 10.3389/fpsyg.2013.00015.

Chiew KS, Braver TS. 2014. Dissociable influences of reward motivation and positive emotion on cognitive control. Cognitive, Affective, \& Behavioral Neuroscience 14(2):509-529 DOI 10.3758/s13415-014-0280-0.

Cohen N, Moyal N, Henik A. 2015. Executive control suppresses pupillary responses to aversive stimuli. Biological Psychology 112:1-11 DOI 10.1016/j.biopsycho.2015.09.006.

Colman F, Paivio A. 1970. Pupillary dilation and mediation processes during paired-associate learning. Canadian Journal of Psychology 24(4):261-270 DOI 10.1037/h0082862. 
Dabbs JM. 1997. Testosterone and pupillary response to auditory sexual stimuli. Physiology and Behavior 62(4):909-912.

Dal Monte O, Costa VD, Noble PL, Murray EA, Averbeck BB. 2015. Amygdala lesions in rhesus macaques decrease attention to threat. Nature Communications 6:10161 DOI 10.1038/ncomms10161.

Damsma A, Van Rijn H. 2017. Pupillary response indexes the metrical hierarchy of unattended rhythmic violations. Brain and Cognition 111:95-103 DOI 10.1016/j.bandc.2016.10.004.

D’Ascenzo S, Iani C, Guidotti R, Laeng B, Rubichi S. 2016. Practice-induced and sequential modulations in the Simon task: evidence from pupil dilation. International Journal of Psychophysiology 110:187-193 DOI 10.1016/j.ijpsycho.2016.08.002.

De Gee JW, Knapen T, Donner TH. 2014. Decision-related pupil dilation reflects upcoming choice and individual bias. Proceedings of the National Academy of Sciences of the United States of America 111(5):E618-E625 DOI 10.1073/pnas.1317557111.

Demberg V, Sayeed A. 2016. The frequency of rapid pupil dilations as a measure of linguistic processing difficulty. PLOS ONE 11(1):e014619 DOI 10.1371/journal.pone.0146194.

Diede NT, Bugg JM. 2017. Cognitive effort is modulated outside of the explicit awareness of conflict frequency: evidence from pupillometry. Journal of Experimental Psychology: Learning, Memory, and Cognition 43(5):824-835 DOI 10.1037/xlm0000349.

Dionisio DP, Granholm E, Hillix WA, Perrine WF. 2001. Differentiation of deception using pupillary responses as an index of cognitive processing. Psychophysiology 38(2):205-211 DOI 10.1017/S0048577201990717.

Ebitz RB, Pearson JM, Platt ML. 2014. Pupil size and social vigilance in rhesus macaques. Frontiers in Neuroscience 8:Article 100 DOI 10.3389/fnins.2014.00100.

Ebitz RB, Platt ML, Ebitz RB, Platt ML. 2015. Neuronal activity in primate dorsal anterior cingulate cortex signals task conflict and predicts adjustments in pupillinked arousal. Neuron 85(3):628-640 DOI 10.1080/10810730902873927.

Einhäuser W, Koch C, Carter OL. 2010. Pupil dilation betrays the timing of decisions. Frontiers in Human Neuroscience 4:Article 18 DOI 10.3389/fnhum.2010.00018.

Elschner SG, Hübner R, Dambacher M. 2017. Do fluency-induced pupillary responses reflect aesthetic affect? Psychology of Aesthetics, Creativity, and the Arts 12(3):294-303 DOI 10.1037/aca0000139.

Engelhardt PE, Ferreira F, Patsenko EG. 2010. Pupillometry reveals processing load during spoken language comprehension. The Quarterly Journal of Experimental Psychology 63(4):639-645 DOI 10.1080/17470210903469864.

Fehrenbacher DD, Djamasbi S. 2017. Information systems and task demand: an exploratory pupillometry study of computerized decision making. Decision Support Systems 97:1-11 DOI 10.1016/j.dss.2017.02.007.

Fernández G, Biondi J, Castro S, Agamenonni O. 2016. Pupil size behavior during online processing of sentences. Journal of Integrative Neuroscience 15(04):485-496 DOI 10.1142/S0219635216500266. 
Ferrari V, De Cesarei A, Mastria S, Lugli L, Baroni G, Nicoletti R, Codispoti M. 2016. Novelty and emotion: pupillary and cortical responses during viewing of natural scenes. Biological Psychology 113:75-82 DOI 10.1016/j.biopsycho.2015.11.008.

Foroughi CK, Sibley C, Coyne JT. 2017. Pupil size as a measure of within-task learning. Psychophysiology 54(10):1436-1443 DOI 10.1111/psyp.12896.

Franklin MS, Broadway JM, Mrazek MD, Smallwood J, Schooler JW. 2013. Window to the wandering mind: pupillometry of spontaneous thought while reading. The Quarterly Journal of Experimental Psychology 66(12):2289-2294 DOI 10.1080/17470218.2013.858170.

Geng JJ, Blumenfeld Z, Tyson TL, Minzenberg MJ. 2015. Pupil diameter reflects uncertainty in attentional selection during visual search. Frontiers in Human Neuroscience 9:Article 435 DOI 10.3389/fnhum.2015.00435.

Geva R, Zivan M, Warsha A, Olchik D. 2013. Alerting, orienting or executive attention networks: differential patters of pupil dilations. Frontiers in Behavioral Neuroscience 7:Article 145 DOI 10.3389/fnbeh.2013.00145.

Gingras B, Marin MM, Puig-Waldmüller E, Fitch WT. 2015. The eye is listening: musicinduced arousal and individual differences predict pupillary responses. Frontiers in Human Neuroscience 9:Article 619 DOI 10.3389/fnhum.2015.00619.

Goldinger SD, He Y, Papesh MH. 2009. Deficits in cross-race face learning: insights from eye movements and pupillometry. Journal of Experimental Psychology: Learning, Memory, and Cognition 35(5):1105-1122 DOI 10.1037/a0016548.

Gomes CA, Montaldi D, Mayes A. 2015. The pupil as an indicator of unconscious memory: introducing the pupil priming effect. Psychophysiology 52(6):754-769 DOI 10.1111/psyp.12412.

Gouraud J, Delorme A, Berberian B. 2018a. Influence of automation on mind wandering frequency in sustained attention. Consciousness and Cognition 66:54-64 DOI 10.1016/j.concog.2018.09.012.

Gouraud J, Delorme A, Berberian B. 2018b. Out of the loop, in your bubble: mind wandering is independent from automation reliability, but influences task engagement. Frontiers in Human Neuroscience 12:383 DOI 10.3389/fnhum.2018.00383.

Granholm E, Asarnow RF, Sarkin AJ, Dykes KL. 1996. Pupillary responses index cognitive resource limitations. Psychophysiology 33(4):457-461 DOI 10.1111/j.1469-8986.1996.tb01071.

Granholm E, Steinhauer SR. 2004. Pupillometric measures of cognitive and emotional processes. International Journal of Psychophysiology 52(1):1-6 DOI 10.1016/j.ijpsycho.2003.12.001.

Hamel RF. 1974. Female subjective and pupillary reaction to nude male and female figures. The Journal of Psychology Interdisciplinary and Applied 87(2):171-175 DOI 10.1080/00223980.1974.9915687.

Hammerschmidt W, Kagan I, Kulke L, Schacht A. 2018. Implicit reward associations impact face processing: time-resolved evidence from event-related brain potentials and pupil dilations. NeuroImage 179:557-569

DOI 10.1016/j.neuroimage.2018.06.055. 
Hampson RE, Opris I, Deadwyler SA. 2010. Neural correlates of fast pupil dilation in nonhuman primates: relation to behavioral performance and cognitive workload. Behavioural Brain Research 212(1):1-11 DOI 10.1016/j.bbr.2010.03.011.

Harsay HA, Cohen MX, Spaan M, Weeda WD, Nieuwenhuis S, Ridderinkhof KR. 2017. Error blindness and motivational significance: shifts in networks centering on anterior insula co-vary with error awareness and pupil dilation. Behavioural Brain Research 355:24-35 DOI 10.1016/j.bbr.2017.10.030.

Hayes T, Muday JA, Schirillo JA. 2013. Portrait hemispheric laterality measured using pupil diameter and aesthetic judgments. Psychology of Aesthetics, Creativity, and the Arts 7(3):276-284 DOI 10.1037/a0031634.

Heaver B, Hutton SB. 2011. Keeping an eye on the truth? Pupil size changes associated with recognition memory. Memory 19(4):398-405 DOI 10.1080/09658211.2011.575788.

Henderson RR, Bradley MM, Lang PJ. 2014. Modulation of the initial light reflex during affective picture viewing. Psychophysiology 51(9):815-818 DOI 10.1111/psyp.12236.

Henderson RR, Bradley MM, Lang PJ. 2017. Emotional imagery and pupil diameter. Psychophysiology 55(6):e13050 DOI 10.1111/psyp.13050.

Herman P. 1975. The Behr pupil revisited. Anisocoria following cerebrovascular accidents. Stroke 6(6):697-702.

Herweg NA, Sommer T, Bunzeck N. 2017. Retrieval demands adaptively change striatal old/new signals and boost subsequent long-term memory. Journal of Neuroscience 38(3):1315-1317 DOI 10.1523/JNEUROSCI.1315-17.2017.

Hoffing RC, Seitz AR. 2015. Pupillometry as a glimpse into the neurochemical basis of human memory encoding. Journal of Cognitive Neuroscience 27(4):765-774 DOI 10.1162/jocn_a_00749.

Hopstaken JF, Van der Linden D, Bakker AB, Kompier MAJ, Leung YK. 2016. Shifts in attention during mental fatigue: evidence from subjective, behavioral, physiological, and eye-tracking data. Journal of Experimental Psychology: Human Perception and Performance 42(6):878-889 DOI 10.1037/xhp0000189.

Hosseini SMH, Bruno JL, Baker JM, Gundran A, Harbott LK, Gerdes JC, Reiss AL. 2017. Neural, physiological, and behavioral correlates of visuomotor cognitive load. Scientific Reports 7(1):8866 DOI 10.1038/s41598-017-07897.

Huijser S, Van Vugt MK, Taatgen NA. 2018. The wandering self: tracking distracting self-generated thought in a cognitively demanding context. Consciousness and Cognition 58:170-185 DOI 10.1016/j.concog.2017.12.004.

Hyona J, Tommola J, Alaja AM. 1995. Pupil dilation as a measure of processing load in simultaneous interpretation and other language tasks. Quarterly Journal of Experimental Psychology. A, Human Experimental Psychology 48(3):598-612 DOI 10.1080/14640749508401407.

Iacozza S, Costa A, Duñabeitia JA. 2017. What do your eyes reveal about your foreign language? Reading emotional sentences in a native and foreign language. PLOS ONE 12(10):e018602 DOI 10.1371/journal.pone.0186027. 
Iijima A, Honda H, Tomioka K, Bando T. 2014. Evaluation of human state of mind with pupillary responses to emotional pictures. Transactions of Japanese Society for Medical and Biological Engineering 52(Supplement):SY-28 DOI 10.11239/jsmbe.52.SY-27.

Iriki A, Tanaka M, Iwamura Y, Iriki A, Tanaka M, Iwamura Y. 1996. Attention-induced neuronal activity in the monkey somatosensory cortex revealed by pupillometrics. Neuroscience Research 25(2):173-181 DOI 10.1016/S0168-0102\%2896\%2901043-7.

Irons JL, Jeon M, Leber AB. 2017. Pre-stimulus pupil dilation and the preparatory control of attention. PLOS ONE 12(12):e018878 DOI 10.1371/journal.pone.0188787.

Jampel RS. 1960. Convergence, divergence, pupillary reactions and accommodation of the eyes from faradic stimulation of the macaque brain. Journal of Comparative Neurology 115(3):371-399 DOI 10.1002/cne.901150306.

Jepma M, Nieuwenhuis S. 2011. Pupil diameter predicts changes in the explorationexploitation trade-off: evidence for the adaptive gain theory. Journal of Cognitive Neuroscience 23(7):1587-1596 DOI 10.1162/jocn.2010.21548.

Johansson R, Pärnamets P, Bjernestedt A, Johansson M. 2018. Pupil dilation tracks the dynamics of mnemonic interference resolution. Scientific Reports 8(1):4826 DOI 10.1038/s41598-018-23297-3.

Johnson DA. 1971. Pupillary responses during a short-term memory task: cognitive processing, arousal, or both? Journal of Experimental Psychology 90(2):311-318 DOI 10.1037/h0031562.

Joshi S, Li Y, Kalwani RM, Gold JI. 2016. Relationships between pupil diameter and neuronal activity in the locus coeruleus, colliculi, and cingulate cortex. Neuron 89(1):221-234 DOI 10.1016/j.neuron.2015.11.028.

Juris M, Velden M. 1977. The pupillary response to mental overload. Physiological Psychology 5(4):421-424.

Just MA, Carpenter PA. 1993. The intensity dimension of thought: pupillometric indices of sentence processing. Canadian Journal of Experimental Psychology 47(2):310-339.

Kafkas A, Montaldi D. 2011. Recognition memory strength is predicted by pupillary responses at encoding while fixation patterns distinguish recollection from familiarity. The Quarterly Journal of Experimental Psychology 64(10):1971-1989 DOI 10.1080/17470218.2011.588335.

Kafkas A, Montaldi D. 2012. Familiarity and recollection produce distinct eye movement, pupil and medial temporal lobe responses when memory strength is matched. Neuropsychologia 50(13):3080-3093 DOI 10.1016/j.neuropsychologia.2012.08.001.

Kafkas A, Montaldi D. 2015. The pupillary response discriminates between subjective and objective familiarity and novelty. Psychophysiology 52(10):1305-1316 DOI 10.1111/psyp.12471.

Kahneman D, Onuska L, Wolman RE. 1968. Effects of grouping on the pupillary response in a short-term memory task. The Quarterly Journal of Experimental Psychology 20(3):309-311 DOI 10.1080/14640746808400168. 
Kahya M, Wood TA, Sosnoff JJ, Devos H. 2018. Increased postural demand is associated with greater cognitive workload in healthy young adults: a pupillometry study. Frontiers in Human Neuroscience 12:288 DOI 10.3389/fnhum.2018.00288.

Kang OE, Huffer KE, Wheatley TP. 2014. Pupil dilation dynamics track attention to high-level information. PLOS ONE 9(8):e102463 DOI 10.1371/journal.pone.0102463.

Kang O, Wheatley T. 2017. Pupil dilation patterns spontaneously synchronize across individuals during shared attention. Journal of Experimental Psychology: General 146(4):569-576 DOI 10.1037/xge0000271.

Katidioti I, Borst JP, Taatgen NA. 2014. What happens when we switch tasks: pupil dilation in multitasking. Journal of Experimental Psychology: Applied 20(4):380-396 DOI 10.1037/xap0000031.

Kawasaki A. 1999. Physiology, assessment, and disorders of the pupil. Current Opinion in Ophthalmology 10(6):394-400 DOI 10.1097/00055735-199912000-00005.

Kinner VL, Kuchinke L, Dierolf AM, Merz CJ, Otto T, Wolf OT. 2017. What our eyes tell us about feelings: tracking pupillary responses during emotion regulation processes. Psychophysiology 54(4):508-518 DOI 10.1111/psyp.12816.

Klingner J, Tversky B, Hanrahan P. 2011. Effects of visual and verbal presentation on cognitive load in vigilance, memory, and arithmetic tasks. Psychophysiology 48(3):323-332 DOI 10.1111/j.1469-8986.2010.01069.

Kloosterman NA, Meindertsma T, Van Loon AM, Lamme VAF, Bonneh YS, Donner TH. 2015. Pupil size tracks perceptual content and surprise. European Journal of Neuroscience 41(8):1068-1078 DOI 10.1111/ejn.12859.

Koelewijn T, De Kluiver H, Shinn-Cunningham BG, Zekveld AA, Kramer SE. 2015. The pupil response reveals increased listening effort when it is difficult to focus attention. Hearing Research 323:81-90 DOI 10.1016/j.heares.2015.02.004.

Koelewijn T, Zekveld AA, Festen JM, Kramer SE. 2012a. Pupil dilation uncovers extra listening effort in the presence of a single-talker masker. Ear and Hearing 33(2):291-300 DOI 10.1097/AUD.0b013e3182310019.

Koelewijn T, Zekveld AA, Festen JM, Rönnberg J, Kramer SE. 2012b. Processing load induced by informational masking is related to linguistic abilities. International Journal of Otolaryngology 2012:Article 865731 DOI 10.1155/2012/865731.

Koenig S, Uengoer M, Lachnit H. 2018. Pupil dilation indicates the coding of past prediction errors: evidence for attentional learning theory. Psychophysiology 55(4):e13020 DOI 10.1111/psyp.13020.

Krach S, Kamp-Becker I, Einhäuser W, Sommer J, Frässle S, Jansen A, Rademacher L, Müller-Pinzler L, Gazzola V, Paulus FM. 2015. Evidence from pupillometry and fMRI indicates reduced neural response during vicarious social pain but not physical pain in autism. Human Brain Mapping 36(11):4730-4744 DOI 10.1002/hbm.22949.

Kramer SE, Lorens A, Coninx F, Zekveld AA, Piotrowska A, Skarzynski H. 2013. Processing load during listening: the influence of task characteristics on the pupil response. Language and Cognitive Processes 28(4):426-442 DOI 10.1080/01690965.2011.642267. 
Kret ME. 2017. The role of pupil size in communication. Is there room for learning? Cognition \& Emotion 32(5):1139-1135 DOI 10.1080/02699931.2017.1370417.

Kret ME, Stekelenburg JJ, Roelofs K, De Gelder B. 2013. Perception of face and body expressions using electromyography, pupillometry and gaze measures. Frontiers in Psychology 4:Article 28 DOI 10.3389/fpsyg.2013.00028.

Kuchinke L, Trapp S, Jacobs AM, Leder H. 2009. Pupillary Responses in art appreciation: effects of aesthetic emotions. Psychology of Aesthetics, Creativity, and the Arts 3(3):156-163 DOI 10.1037/a0014464.

Kuchinke L, Võ MLH, Hofmann M, Jacobs AM. 2007. Pupillary responses during lexical decisions vary with word frequency but not emotional valence. International Journal of Psychophysiology 65(2):132-140 DOI 10.1016/j.ijpsycho.2007.04.004.

Kuipers JR, Thierry G. 2011. N400 amplitude reduction correlates with an increase in pupil size. Frontiers in Human Neuroscience 5:Article 61 DOI 10.3389/fnhum.2011.00061.

Kuniecki M, Wołoszyn K, Domagalik A, Pilarczyk J. 2018. Disentangling brain activity related to the processing of emotional visual information and emotional arousal. Brain Struct Funct 223(4):1589-1597 DOI 10.1007/s00429-017-1576.

Laeng B, Eidet LM, Sulutvedt U, Panksepp J. 2016. Music chills: the eye pupil as a mirror to music's soul. Consciousness and Cognition 44:161-178

DOI 10.1016/j.concog.2016.07.009.

Laeng B, Endestad T. 2012. Bright illusions reduce the eye's pupil. Proceedings of the National Academy of Sciences of the United States of America 109(6):2162-2167 DOI 10.1073/pnas.1118298109.

Laeng B, Ørbo M, Holmlund T, Miozzo M. 2011. Pupillary Stroop effects. Cognitive Processing 12(1):13-21 DOI 10.1007/s10339-010-0370.

Laeng B, Sirois S, Gredebäck G. 2012. Pupillometry: a window to the preconscious? Perspectives on Psychological Science 7(1):18-27 DOI 10.1177/1745691611427305.

Laeng B, Sulutvedt U. 2014. The eye pupil adjusts to imaginary light. Psychological Science 25(1):188-197 DOI 10.1177/0956797613503556.

Landgraf S, Raisig S, Van Der Meer E. 2012. Discerning temporal expectancy effects in script processing: evidence from pupillary and eye movement recordings. Journal of the International Neuropsychological Society 18(2):351-360 DOI 10.1017/S1355617711001809.

Lehmann SJ, Corneil BD. 2016. Transient pupil dilation after subsaccadic microstimulation of primate frontal eye fields. Journal of Neuroscience 36(13):3765-3776 DOI 10.1523/JNEUROSCI.4264-15.2016.

Lempert KM, Chen YL, Fleming SM. 2015. Relating pupil dilation and metacognitive confidence during auditory decision-making. PLOS ONE 10(5):e012658 DOI 10.1371/journal.pone.0126588.

Leuchs L, Schneider M, Spoormaker VI. 2018. Measuring the conditioned response: a comparison of pupillometry, skin conductance, and startle electromyography. Psychophysiology 56(1):1-16 DOI 10.1111/psyp.13283. 
Liao H-I, Yoneya M, Kidani S, Kashino M, Furukawa S. 2016. Human pupillary dilation response to deviant auditory stimuli: effects of stimulus properties and voluntary attention. Frontiers in Neuroscience 10:536-543 DOI 10.3389/fnins.2016.00043.

Liberati A, Altman DG, Tetzlaff J, Mulrow C, Gotzsche PC, Ioannidis JPA, Clarke M, Devereaux PJ, Kleijnen J, Moher D. 2009. The PRISMA statement for reporting systematic reviews and meta-analyses of studies that evaluate health care interventions: explanation and elaboration. Journal of Clinical Epidemiology 62(10):e1-e34 DOI 10.1016/j.jclinepi.2009.06.006.

Lichtenstein-Vidne L, Gabay S, Cohen N, Henik A. 2017. Lateralisation of emotions: evidence from pupil size measurement. Cognition \& Emotion 31(4):699-711 DOI 10.1080/02699931.2016.1164668.

Lim JKH, Li Q-X, He Z, Vingrys AJ, Wong VHY, Currier N, Mullen J, Bui BV, Nguyen CTO. 2016. The eye as a biomarker for Alzheimer's disease. Frontiers in Neuroscience 10:Article 536 DOI 10.3389/fnins.2016.00536.

Lin H, Saunders B, Hutcherson CA, Inzlicht M. 2017. Midfrontal theta and pupil dilation parametrically track subjective conflict (but also surprise) during intertemporal choice. NeuroImage 172:838-852 DOI 10.1016/j.neuroimage.2017.10.055.

Lobben M, Bochynska A. 2018. Grounding by attention simulation in peripersonal space: pupils dilate to pinch grip but not big size nominal classifier. Cognitive Science 42(2):576-599 DOI 10.1111/cogs.12524.

Magliero A. 1983. Pupil dilations following pairs of identical and related to-beremembered words. Memory \& Cognition 11(6):609-615.

Manohar SG, Husain M, Manohar SG, Husain M, Manohar SG, Husain M. 2016. Human ventromedial prefrontal lesions alter incentivisation by reward. Cortex 76:104-120 DOI 10.1016/j.cortex.2016.01.005.

Marois A, Labonté K, Parent M, Vachon F. 2018. Eyes have ears: indexing the orienting response to sound using pupillometry. International Journal of Psychophysiology 123:152-162 DOI 10.1016/j.ijpsycho.2017.09.016.

Marquart G, De Winter J. 2015. Workload assessment for mental arithmetic tasks using the task-evoked pupillary response. PeerJ 1:e16 DOI 10.7717/peerj-cs.16.

Massar SAA, Sasmita K, Lim J, Chee MWL. 2018. Motivation alters implicit temporal attention through sustained and transient mechanisms: a behavioral and pupillometric study. Psychophysiology 55(12):e13275 DOI 10.1111/psyp.13275.

Mathôt S, Dalmaijer E, Grainger J, Van der Stigchel S. 2014. The pupillary light response reflects exogenous attention and inhibition of return. Journal of Vision 14(14):Article 7 DOI 10.1167/14.14.7.

Mathôt S, Grainger J, Strijkers K. 2017. Pupillary responses to words that convey a sense of brightness or darkness. Psychological Science 28(8):1116-1124 DOI 10.1177/0956797617702699.

Mathôt S, Melmi J-B, Van der Linden L, Van der Stigchel S. 2016. The mind-writing pupil: a human-computer interface based on decoding of covert attention through pupillometry. PLOS ONE 11(2):e014880 DOI 10.1371/journal.pone.0148805. 
Mathôt S, Van der Linden L, Grainger J, Vitu F. 2013. The pupillary light response reveals the focus of covert visual attention. PLOS ONE 8(10):e78168 DOI 10.1371/journal.pone.0078168.

McCloy DR, Lau BK, Larson E, Pratt KAI, Lee AKC. 2017. Pupillometry shows the effort of auditory attention switching. Journal of the Acoustical Society of America 141(4):Article 2440 DOI 10.1121/1.4979340.

Metalis SA, Hess EH. 1982. Pupillary response/semantic differential scale relationships. Journal of Research in Personality 16(2):201-216 DOI 10.1016/0092-6566(82)90076-9.

Metalis SA, Rhoades BK, Hess EH, Petrovich SB. 1980. Pupillometric assessment of reading using materials in normal and reversed orientations. Journal of Applied Psychology 65(3):359-363 DOI 10.1037/0021-9010.65.3.359.

Mill RD, O'Connor AR, Dobbins IG. 2016. Pupil dilation during recognition memory: isolating unexpected recognition from judgment uncertainty. Cognition 154:81-94 DOI 10.1016/j.cognition.2016.05.018.

Mitra R, McNeal KS, Bondell HD. 2017. Pupillary response to complex interdependent tasks: a cognitive-load theory perspective. Behavior Research Methods 49(5):1905-1919 DOI 10.3758/s13428-016-0833.

Montefinese M, Ambrosini E, Fairfield B, Mammarella N. 2013. The "subjective" pupil old/new effect: is the truth plain to see? International Journal of Psychophysiology 89(1):48-56 DOI 10.1016/j.ijpsycho.2013.05.001.

Montefusco-Siegmund R, Leonard TK, Hoffman KL. 2017. Hippocampal gammaband Synchrony and pupillary responses index memory during visual search. Hippocampus 27(4):425-434 DOI 10.1002/hipo.22702.

Moresi S, Adam JJ, Rijcken J, Van Gerven PWM, Kuipers H, Jolles J. 2008. Pupil dilation in response preparation. International Journal of Psychophysiology 67(2):124-130 DOI 10.1016/j.ijpsycho.2007.10.011.

Morey CC. 2018. Perceptual grouping boosts visual working memory capacity and reduces effort during retention. British Journal of Psychology 110(2):306-327 DOI 10.1111/bjop.12355.

Murphy PR, O'Connell RG, O’Sullivan M, Robertson IH, Balsters JH. 2014. Pupil diameter covaries with BOLD activity in human locus coeruleus. Human Brain Mapping 35(8):4140-4154 DOI 10.1002/hbm.22466.

Naber M, Alvarez GA, Nakayama K. 2013. Tracking the allocation of attention using human pupillary oscillations. Frontiers in Psychology 4:Article 919 DOI 10.3389/fpsyg.2013.00919.

Naber M, Frassle S, Rutishauser U, Einhauser W. 2013. Pupil size signals novelty and predicts later retrieval success for declarative memories of natural scenes. Journal of Vision 13(2):11 DOI 10.1167/13.2.11.

Naber M, Nakayama K. 2013. Pupil responses to high-level image content. Journal of Vision 13(6):7 DOI 10.1167/13.6.7. 
Nowack K, Milfont TL, Van der Meer E. 2013. Future versus present: time perspective and pupillary response in a relatedness judgment task investigating temporal event knowledge. International Journal of Psychophysiology 87(2):173-182 DOI 10.1016/j.ijpsycho.2012.12.006.

Nunnally JC, Knott PD, Duchnowski A, Parker R. 1967. Pupillary response as a general measure of activation. Perception \& Psychophysics 2(4):149-155 DOI 10.3758/BF03210310.

Nuthmann A, Van der Meer E. 2005. Time's arrow and pupillary response. Psychophysiology 42(3):306-317 DOI 10.1111/j.1469-8986.2005.00291.

Ojha A, Indurkhya B, Lee M. 2017. Intelligence level and the allocation of resources for creative tasks: a pupillometry study. Creativity Research Journal 29(1):78-85 DOI 10.1080/10400419.2017.1263502.

Oliva M, Anikin A. 2018. Pupil dilation reflects the time course of emotion recognition in human vocalizations. Scientific Reports 8(1):4871 DOI 10.1038/s41598-018-23265.

Otero SC, Weekes BS, Hutton SB. 2011. Pupil size changes during recognition memory. Psychophysiology 48(10):1346-1353 DOI 10.1111/j.1469-8986.2011.01217.

Paivio A, Simpson HM. 1966. The effect of word abstractness and pleasantness on pupil size during an imagery task. Psychonomic Science 5(2):55-56 DOI 10.3758/BF03328277.

Papesh MH, Goldinger SD. 2012. Pupil-BLAH-metry: cognitive effort in speech planning reflected by pupil dilation. Attention, Perception, Psychophys 74(4):754-765 DOI 10.3758/s13414-011-0263.

Park S, Whang M. 2018. Infrared camera-based non-contact measurement of brain activity from pupillary rhythms. Frontiers in Physiology 9:Article 1400 DOI 10.3389/fphys.2018.01400.

Pearlstein JG, Johnson SL, Modavi K, Peckham AD, Carver CS. 2018. Neurocognitive mechanisms of emotion-related impulsivity: the role of arousal. Psychophysiology 56(2):e13293 DOI 10.1111/psyp.13293.

Peinkhofer C, Martens P, Grand J, Truelsen T, Knudsen GM, Kjaergaard J, Kondziella D. 2018. Influence of strategic cortical infarctions on pupillary function. Frontiers in Neurology 9:916 DOI 10.3389/fneur.2018.00916.

Piquado T, Isaacowitz D, Wingfield A. 2010. Pupillometry as a measure of cognitive effort in younger and older adults. Psychophysiology 47(3):560-569 DOI 10.1111/j.1469-8986.2009.00947.

Porter G, Hood BM, Troscianko T. 2006. Females, but not males, show greater pupillary response to direct- than deviated-gaze faces. Perception 35(8):1129-1136 DOI 10.1068/p5438.

Porter G, Tales A, Troscianko T, Wilcock G, Haworth J, Leonards U. 2010. New insights into feature and conjunction search: I. Evidence from pupil size, eye movements and ageing. Cortex 46(5):621-636 DOI 10.1016/j.cortex.2009.04.013.

Powell WR, Schirillo JA. 2011. Hemispheric laterality measured in Rembrandt's portraits using pupil diameter and aesthetic verbal judgements. Cognition \& Emotion 25(5):868-885 DOI 10.1080/02699931.2010.515709. 
Prehn K, Heekeren HR, Van der Meer E. 2011. Influence of affective significance on different levels of processing using pupil dilation in an analogical reasoning task. International Journal of Psychophysiology 79(2):236-243 DOI 10.1016/j.ijpsycho.2010.10.014.

Quirins M, Marois C, Valente M, Seassau M, Weiss N, Karoui IE, Hochmann J-R, Naccache L. 2018. Conscious processing of auditory regularities induces a pupil dilation. Scientific Reports 8(1):14819 DOI 10.1038/s41598-018-33202-7.

Raisig S, Welke T, Hagendorf H, Van der Meer E. 2010. I spy with my little eye: detection of temporal violations in event sequences and the pupillary response. International Journal of Psychophysiology 76(1):1-8 DOI 10.1016/j.ijpsycho.2010.01.006.

Raisig S, Welke T, Hagendorf H, Van Der Meer E. 2007. Investigating dimensional organization in scripts using the pupillary response. Psychophysiology 44(6):864-873 DOI 10.1111/j.1469-8986.2007.00592.

Reilly J, Kelly A, Kim SH, Jett S, Zuckerman B. 2018. The human task-evoked pupillary response function is linear: implications for baseline response scaling in pupillometry. Behavior Research Methods 51(2):865-878 DOI 10.3758/s13428-018-1134-4.

Reiner M, Gelfeld TM. 2014. Estimating mental workload through event-related fluctuations of pupil area during a task in a virtual world. International Journal of Psychophysiology 93(1):38-44 DOI 10.1016/j.ijpsycho.2013.11.002.

Reinhard G, Lachnit H. The effect of stimulus probability on pupillary response as an indicator of cognitive processing in human learning and categorization. Biological Psychology 60(2-3):199-215 DOI 10.1016/S0301-0511(02)00031-5 (accessed on 18 April 2018).

Reinhard G, Lachnit H, König S. 2006. Tracking stimulus processing in Pavlovian pupillary conditioning. Psychophysiology 43(1):73-83

DOI 10.1111/j.1469-8986.2006.00374.

Ribeiro MJ, Castelo-Branco M. 2019. Age-related differences in event-related potentials and pupillary responses in cued reaction time tasks. Neurobiology of Aging 73:177-189 DOI 10.1016/j.neurobiolaging.2018.09.028.

Rieger G, Savin-Williams RC. 2012. The eyes have it: sex and sexual orientation differences in pupil dilation patterns. PLOS ONE 7(8):e40256 DOI 10.1371/journal.pone.0040256.

Rigato S, Rieger G, Romei V. 2016. Multisensory signalling enhances pupil dilation. Scientific Reports 6(1):26188 DOI 10.1038/srep26188.

Robison MK, Unsworth N. 2018. Pupillometry tracks fluctuations in working memory performance. Attention, Perception, \& Psychophysics 81(2):407-419 DOI 10.3758/s13414-018-1618-4.

Rosa PJ, Oliveira J, Alghazzawi D, Fardoun H, Gamito P. 2017. Affective and physiological correlates of the perception of unimodal and bimodal emotional stimuli Pedro. Psicothema 29(3):364-369 DOI 10.7334/psicothema2016.272.

Samuels E, Szabadi E. 2008. Functional neuroanatomy of the noradrenergic locus coeruleus: its roles in the regulation of arousal and autonomic function part I: 
principles of functional organisation. Current Neuropharmacology 6(3):235-253

DOI 10.2174/157015908785777229.

Satterthwaite TD, Green L, Myerson J, Parker J, Ramaratnam M, Buckner RL. 2007.

Dissociable but inter-related systems of cognitive control and reward during decision making: evidence from pupillometry and event-related fMRI. NeuroImage 37(3):1017-1031 DOI 10.1016/j.neuroimage.2007.04.066.

Schardt C, Adams MB, Owens T. 2007. Utilization of the PICO framework to improve searching PubMed for clinical questions. BioMed Central 7:16

DOI 10.1186/1472-6947-7-16.

Scheepers C, Mohr S, Fischer MH, Roberts AM. 2013. Listening to Limericks: a pupillometry investigation of perceivers' expectancy. PLOS ONE 8(9):e74986 DOI 10.1371/journal.pone.0074986.

Schirillo JA. 2014. Pupil dilations reflect why rembrandt biased female portraits leftward and males rightward. Frontiers in Human Neuroscience 7:Article 938

DOI 10.3389/fnhum.2013.00938.

Schlag J, Dassonville P, Schlag-Rey M. 1998. Interaction of the two frontal eye fields before saccade onset. Journal of Neurophysiology 79(1):64-72

DOI 10.1152/jn.1998.79.1.64.

Schlemmer KB, Kulke F, Kuchinke L, Van Der Meer E. 2005. Absolute pitch and pupillary response: effects of timbre and key color. Psychophysiology 42(4):465-472

DOI 10.1111/j.1469-8986.2005.00306.

Schluroff M, Zimmermann TE, Freeman RB, Hofmeister K, Lorscheid T, Weber A. 1986. Pupillary responses to syntactic ambiguity of sentences. Brain and Language 27(2):322-344 DOI 10.1016/0093-934X\%2886\%2990023-4.

Schmidtke J. 2014. Second language experience modulates word retrieval effort in bilinguals: evidence from pupillometry. Frontiers in Psychology 5:Article 137 DOI 10.3389/fpsyg.2014.00137.

Schneider CB, Ziemssen T, Schuster B, Seo HS, Haehner A, Hummel T. 2009. Pupillary responses to intranasal trigeminal and olfactory stimulation. Journal of Neural Transmission 116(7):885-889 DOI 10.1007/s00702-009-0244-7.

Schneider M, Hathway P, Leuchs L, Samann PG, Czisch M, Spoormaker VI. 2016. Spontaneous pupil dilations during the resting state are associated with activation of the salience network. NeuroImage 139:189-201

DOI 10.1016/j.neuroimage.2016.06.011.

Schneider M, Leuchs L, Czisch M, Samann PG, Spoormaker VI. 2018. Disentangling reward anticipation with simultaneous pupillometry/fMRI. NeuroImage 178:11-22 DOI 10.1016/j.neuroimage.2018.04.078.

Schrammel F, Pannasch S, Graupner ST, Mojzisch A, Velichkovsky BM. 2009. Virtual friend or threat? The effects of facial expression and gaze interaction on psychophysiological responses and emotional experience. Psychophysiology 46(5):922-931 DOI 10.1111/j.1469-8986.2009.00831. 
Sevilla Y, Maldonado M, Shalóm DE. 2014. Pupillary dynamics reveal computational cost in sentence planning. The Quarterly Journal of Experimental Psychology 67(6):1041-1052 DOI 10.1080/17470218.2014.911925.

Seymour TL, Baker CA, Gaunt JT. 2013. Combining blink, pupil, and response time measures in a concealed knowledge test. Frontiers in Psychology 3:614 DOI 10.3389/fpsyg.2012.00614.

Shalev L, Paz R, Avidan G, Lee S, Rony P, Galia A. 2018. Visual aversive learning compromises sensory discrimination. Journal of Neuroscience 38(11):2766-2779 DOI 10.1523/JNEUROSCI.0889-17.2017.

Sher MA. 1971. Pupillary dilation before and after interruption of familiar and unfamiliar sequences. Journal of Personality and Social Psychology 20(3):281-286 DOI 10.1037/h0031807.

Siegle GJ, D’Andrea W, Jones N, Hallquist MN, Stepp SD, Fortunato A, Morse JQ, Pilkonis PA. 2015. Prolonged physiological reactivity and loss: association of pupillary reactivity with negative thinking and feelings. International Journal of Psychophysiology 98(2):310-320 DOI 10.1016/j.ijpsycho.2015.05.009.

Simpson HM, Hale SM. 1969. Pupillary changes during a decision-making task. Perceptual and Motor Skills 29(2):495-498 DOI 10.2466/pms.1969.29.2.495.

Simpson HM, Paivio A. 1968. Effects on pupil size of manual and verbal indicators of cognitive task fulfillment. Perception \& Psychophysics 3(3):185-190 DOI 10.3758/BF03212726.

Smallwood J, Brown KS, Tipper C, Giesbrecht B, Franklin MS, Mrazek MD, Carlson JM, Schooler JW. 2011. Pupillometric evidence for the decoupling of attention from perceptual input during offline thought. PLOS ONE 3:e18298 DOI 10.1371/journal.pone.0018298.

Snowden RJ, O'Farrell KR, Burley D, Erichsen JT, Newton NV, Gray NS. 2016. The pupil's response to affective pictures: role of image duration, habituation, and viewing mode. Psychophysiology 53(8):1217-1223 DOI 10.1111/psyp.12668.

Sperandio I, Bond N, Binda P. 2018. Pupil size as a gateway into conscious interpretation of brightness. Frontiers in Neurology 9:1070 DOI 10.3389/fneur.2018.01070.

Stanners RF, Coulter M, Sweet AW, Murphy P. 1979. The pupillary response as an indicator of arousal and cognition. Motivation and Emotion 3(4):319-340 DOI 10.1007/BF00994048.

Starc M, Anticevic A, Repovš G. 2017. Fine-grained versus categorical: pupil size differentiates between strategies for spatial working memory performance. Psychophysiology 54(5):724-735 DOI 10.1111/psyp.12828.

Steiner GZ, Barry RJ. 2011. Pupillary responses and event-related potentials as indices of the orienting reflex. Psychophysiology 48(12):1648-1655 DOI 10.1111/j.1469-8986.2011.01271.

Steinhauer SR, Condray R, Kasparek A. 2000. Cognitive modulation of midbrain function: task-induced reduction of the pupillary light reflex. International Journal of Psychophysiology 39(1):21-30 DOI 10.1016/S0167-8760(00)00119-7. 
Steinhauer SR, Siegle GJ, Condray R, Pless M. 2004. Sympathetic and parasympathetic innervation of pupillary dilation during sustained processing. International Journal of Psychophysiology 52(1):77-86 DOI 10.1016/j.ijpsycho.2003.12.005.

Stelmack RM, Siddle DAT. 1982. Pupillary dilation as an index of the orienting reflex. Psychophysiology 19(6):706-708 DOI 10.1111/j.1469-8986.1982.tb02529.

Stojmenova K, Sodnik J. 2018. Validation of auditory detection-response task method for assessing the attentional effects of cognitive load. Traffic Injury Prevention 19(5):495-500 DOI 10.1080/15389588.2018.1439164.

Sulutvedt U, Mannix TK, Laeng B. 2018. Gaze and the eye pupil adjust to imagined size and distance. Cognitive Science 42(8):3159-3176 DOI 10.1111/cogs.12684.

Suzuki TW, Kunimatsu J, Tanaka M. 2016. Correlation between pupil size and subjective passage of time in non-human primates. Journal of Neuroscience 36(44):11331-11337 DOI 10.1523/JNEUROSCI.2533-16.2016.

Szulewski A, Gegenfurtner A, Howes DW, Sivilotti MLA, Van Merriënboer JJG. 2017. Measuring physician cognitive load: validity evidence for a physiologic and a psychometric tool. Advances in Health Sciences Education. Theory and Practice 22(4):951-968 DOI 10.1007/s10459-016-9725-2.

Szulewski A, Roth N, Howes D. 2015. The use of task-evoked pupillary response as an objective measure of cognitive load in novices and trained physicians: a new tool for the assessment of expertise. Academic Medicine 90(7):981-987 DOI 10.1097/ACM.0000000000000677.

Taylor JS. 1981. Pupillary response to auditory versus visual mental loading: a pilot study using super 8-Mm photography. Perceptual and Motor Skills 52(2):425-426 DOI 10.2466/pms.1981.52.2.425.

Thoma D, Baum A. 2018. Reduced language processing automaticity induces weaker emotions in Bilinguals regardless of learning context. Emotion Epub ahead of print Sep 132018 DOI 10.1037/emo0000502.

Trani A, Verhaeghen P. 2018. Foggy windows: pupillary responses during task preparation. The Quarterly Journal of Experimental Psychology 71(10):2235-2248 DOI 10.1177/1747021817740856.

Tromp J, Hagoort P, Meyer AS. 2016. Pupillometry reveals increased pupil size during indirect request comprehension. The Quarterly Journal of Experimental Psychology 69(6):1093-1108 DOI 10.1080/17470218.2015.1065282.

Tsukahara JS, Harrison TL, Engle RW. 2016. The relationship between baseline pupil size and intelligence. Cognitive Psychology 91:109-123 DOI 10.1016/j.cogpsych.2016.10.001.

Turi M, Burr DC, Binda P. 2018. Pupillometry reveals perceptual differences that are tightly linked to autistic traits in typical adults. Elife 7:e32399 DOI 10.7554/eLife.32399.

Tylén K, Allen M, Hunter BK, Roepstorff A. 2012. Interaction vs. observation: distinctive modes of social cognition in human brain and behavior? A combined fMRI and eye-tracking study. Frontiers in Human Neuroscience 6:Article 331 DOI 10.3389/fnhum.2012.00331. 
Unsworth N, Robison MK. 2016. Pupillary correlates of lapses of sustained attention. Cognitive, Affective, \& Behavioral Neuroscience 16(4):601-615 DOI 10.3758/s13415-016-0417-4.

Unsworth N, Robison MK. 2018a. Tracking arousal state and mind wandering with pupillometry. Cognitive, Affective, \& Behavioral Neuroscience 18(4):638-664 DOI 10.3758/s13415-018-0594-4.

Unsworth N, Robison MK. 2018b. Tracking working memory maintenance with pupillometry. Attention, Perception, \& Psychophysics 80(2):461-484 DOI 10.3758/s13414-017-1455.

Unsworth N, Robison MK, Miller AL. 2018. Pupillary correlates of fluctuations in sustained attention. Journal of Cognitive Neuroscience 26(3):1-13 DOI 10.1162/jocn_a_01251.

Urry HL, Van Reekum CM, Johnstone T, Davidson RJ. 2009. Individual differences in some (but not all) medial prefrontal regions reflect cognitive demand while regulating unpleasant emotion. NeuroImage 47(3):852-863 DOI 10.1016/j.neuroimage.2009.05.069.

Vanderhasselt MA, De Raedt R, Nasso S, Puttevils L, Mueller SC. 2018. Don't judge me: psychophysiological evidence of gender differences to social evaluative feedback. Biological Psychology 135:29-35 DOI 10.1016/j.biopsycho.2018.02.017.

Vanderhasselt M-A, Remue J, Ng KK, De Raedt R. 2014. The interplay between the anticipation and subsequent online processing of emotional stimuli as measured by pupillary dilatation: the role of cognitive reappraisal. Frontiers in Psychology 5:Article 207 DOI 10.3389/fpsyg.2014.00207.

Van Der Meer E, Friedrich M, Nuthmann A, Stelzel C, Kuchinke L. 2003. Picture-word matching: flexibility in conceptual memory and pupillary responses. Psychophysiology 40(6):904-913 DOI 10.1111/1469-8986.00108.

Van der Wel P, Van Steenbergen H. 2018. Pupil dilation as an index of effort in cognitive control tasks: a review. Psychonomic Bulletin \& Review 25(6):2005-2015 DOI 10.3758/s13423-018-1432-y.

Van Gerven PWM, Paas F, Van Merriënboer JJG, Schmidt HG. 2004. Memory load and the cognitive pupillary response in aging. Psychophysiology 41(2):167-174 DOI 10.1111/j.1469-8986.2003.00148.

Van Rijn H, Dalenberg JR, Borst JP, Sprenger SA. 2012. Pupil dilation co-varies with memory strength of individual traces in a delayed response paired-associate task. PLOS ONE 7(12):e51134 DOI 10.1371/journal.pone.0051134.

Van Steenbergen H, Band GPH. 2013. Pupil dilation in the Simon task as a marker of conflict processing. Frontiers in Human Neuroscience 7:Article 215 DOI 10.3389/fnhum.2013.00215.

Verney SP, Granholm E, Dionisio DP. 2001. Pupillary responses and processing resources on the visual backward masking task. Psychophysiology 38(1):76-83.

Verney SP, Granholm E, Marshall SP. 2004. Pupillary responses on the visual backward masking task reflect general cognitive ability. International Journal of Psychophysiology 52(1):23-36 DOI 10.1016/j.ijpsycho.2003.12.003. 
Võ ML-H, Jacobs AM, Kuchinke L, Hofmann M, Conrad M, Schacht A, Hutzler F. 2008. The coupling of emotion and cognition in the eye: introducing the pupil old/new effect. Psychophysiology 45(1):130-140 DOI 10.1111/j.1469-8986.2007.00606.

Wahn B, Ferris DP, Hairston WD, König P. 2016. Pupil sizes scale with attentional load and task experience in a multiple object tracking task. PLOS ONE 11(12):e016808 DOI 10.1371/journal.pone.0168087.

Wang C-A, Boehnke SE, White BJ, Munoz DP. 2012. Microstimulation of the monkey superior colliculus induces pupil dilation without evoking saccades. Journal of Neuroscience 32(11):3629-3636 DOI 10.1523/JNEUROSCI.5512-11.2012.

Webb AK, Honts CR, Kircher JC, Bernhardt P, Cook AE. 2009. Effectiveness of pupil diameter in a probable-lie comparison question test for deception. Leg Criminal Psychology 14(2):279-292 DOI 10.1348/135532508X398602.

Weiss MW, Trehub SE, Schellenberg EG, Habashi P. 2016. Pupils dilate for vocal or familiar music. Journal of Experimental Psychology: Human Perception and Performance 42(8):1061-1065 DOI 10.1037/xhp0000226.

White O, French RM. 2017. Pupil diameter may reflect motor control and learning. Journal of Motor Behavior 49(2):141-149 DOI 10.1080/00222895.2016.1161593.

Widmann A, Schröger E, Wetzel N. 2018. Emotion lies in the eye of the listener: emotional arousal to novel sounds is reflected in the sympathetic contribution to the pupil dilation response and the P3. Biological Psychology 133:10-17 DOI 10.1016/j.biopsycho.2018.01.010.

Wierda SM, Van Rijn H, Taatgen NA, Martens S. 2012. Pupil dilation deconvolution reveals the dynamics of attention at high temporal resolution. Proceedings of the National Academy of Sciences of the United States of America 109(22):8456-8460 DOI 10.1073/pnas.1201858109.

Willems C, Herdzin J, Martens S. 2015. Individual differences in temporal selective attention as reflected in pupil dilation. PLOS ONE 10(12):e014505 DOI 10.1371/journal.pone.0145056.

Winn MB, Edwards JR, Litovsky RY. 2015. The impact of auditory spectral resolution on listening effort revealed by pupil dilation. Ear and Hearing 36(4):e153-65 DOI 10.1097/AUD.0000000000000145.

Wolff MJ, Scholz S, Akyürek EG, Van Rijn H. 2015. Two visual targets for the price of one? Pupil dilation shows reduced mental effort through temporal integration. Psychonomic Bulletin \& Review 22(1):251-257 DOI 10.3758/s13423-014-0667-5.

Wollner C, Hammerschmidt D, Albrecht H. 2018. Slow motion in films and video clips: music influences perceived duration and emotion, autonomic physiological activation and pupillary responses. PLOS ONE 13(6):e019916 DOI 10.1371/journal.pone.0199161.

Wong HK, Epps J. 2016. Pupillary transient responses to within-task cognitive load variation. Computer Methods and Programs in Biomedicine 137:47-63 DOI 10.1016/j.cmpb.2016.08.017. 
Wright TJ, Boot WR, Morgan CS. 2013. Pupillary response predicts multiple object tracking load, error rate, and conscientiousness, but not inattentional blindness. Acta Psychologica 144(1):6-11 DOI 10.1016/j.actpsy.2013.04.018.

Wu EXW, Laeng B, Magnussen S. 2012. Through the eyes of the own-race bias: eye-tracking and pupillometry during face recognition. Society for Neuroscience 7(2):202-216 DOI 10.1080/17470919.2011.596946.

Wykowska A, Anderl C, Schubö A, Hommel B. 2013. Motivation modulates visual attention: evidence from pupillometry. Frontiers in Psychology 4:Article 59 DOI 10.3389/fpsyg.2013.00059.

Yellin D, Berkovich-Ohana A, Malach R. 2015. Coupling between pupil fluctuations and resting-state fMRI uncovers a slow build-up of antagonistic responses in the human cortex. NeuroImage 106:414-427 DOI 10.1016/j.neuroimage.2014.11.034.

Yih J, Sha H, Beam DE, Parvizi J, Gross JJ. 2018. Reappraising faces: effects on accountability appraisals, self-reported valence, and pupil diameter. Cognition \& Emotion 9:1-10 DOI 10.1080/02699931.2018.1507999.

Yrttiaho S, Niehaus D, Thomas E, Leppänen JM. 2017. Mothers' pupillary responses to infant facial expressions. Behavioral and Brain Functions 13(1):Article 2 DOI 10.1186/s12993-017-0120-9.

Zekveld AA, Festen JM, Kramer SE. 2013. Task difficulty differentially affects two measures of processing load: the pupil response during sentence processing and delayed cued recall of the sentences. Journal of Speech, Language, and Hearing Research 56(4):1156-1165 DOI 10.1044/1092-4388(2012/12-0058.

Zekveld AA, Heslenfeld DJ, Johnsrude IS, Versfeld NJ, Kramer SE. 2014a. The eye as a window to the listening brain: neural correlates of pupil size as a measure of cognitive listening load. NeuroImage 101:76-86 DOI 10.1016/j.neuroimage.2014.06.069.

Zekveld AA, Kramer SE. 2014. Cognitive processing load across a wide range of listening conditions: insights from pupillometry. Psychophysiology 51(3):277-284 DOI 10.1111/psyp.12151.

Zekveld AA, Kramer SE, Festen JM. 2010. Pupil response as an indication of effortful listening: the influence of sentence intelligibility. Ear and Hearing 31(4):480-490 DOI 10.1097/AUD.0b013e3181d4f251.

Zekveld AA, Kramer SE, Ronnberg J, Rudner M. 2018. In a concurrent memory and auditory perception task, the pupil dilation response is more sensitive to memory load than to auditory stimulus characteristics. Ear and Hearing 40(2):272-286 DOI 10.1097/AUD.0000000000000612.

Zekveld AA, Rudner M, Kramer SE, Lyzenga J, Rönnberg J. 2014b. Cognitive processing load during listening is reduced more by decreasing voice similarity than by increasing spatial separation between target and masker speech. Frontiers in Neuroscience 8:Article 88 DOI 10.3389/fnins.2014.00088.

Zellin M, Pannekamp A, Toepel U, Van der Meer E. 2011. In the eye of the listener: pupil dilation elucidates discourse processing. International Journal of Psychophysiology 81(3):133-141 DOI 10.1016/j.ijpsycho.2011.05.009. 